\title{
The syntax of (complex) numerals in Arabic
}

\author{
Hussein Al-Bataineh \& Phil Branigan \\ Memorial University of Newfoundland
}

February 14, 2020

\begin{abstract}
Word order, case assignment, and agreement for gender and number are realised with remarkable complexity in the Arabic numeral system. This paper examines the internal morphological structure of simplex, compound, and complex numerals. We identify a recurrent pattern found both inside complex numerals and in the structural relations between numeral and the nouns they quantify. The structures uncovered then allow for more principled accounts of the superficial morphosyntactic complexities. The analysis suggests that DP contains a single Num head, but that Num can express both additive and multiplicative arithmetic operations.
\end{abstract}

\section{Introduction}

Despite considerable attention in the literature, the syntax of numeral-noun constructions (NNCs) remains a challenging area of research. It remains unclear whether "the syntactic behavior of cardinal numerals falls between that of adjectives and nouns" (Corbett, 1978:61) or they comprise their own distinct categories. Hurford (1975:3) maintains that "probably all languages have as a component something that can be called a numeral system, a system distinct from all other systems in the same language". Scholars analyze cardinals as determiners or generalized quantifiers, predicates, semantic modifiers, and degrees (for a comprehensive view, see Ionin \& Matushansky, 2018:11- 46). Syntactically, cardinals have been considered as (semi)lexical elements showing (some) properties of nouns or adjectives (e.g., Corbett, 1978; Hurford, 1998; Jackendoff, 1977) or as related to functional heads, viz., Q or Num (e.g., Kayne, 2007; Ritter, 1992; Rutkowski \& Szczegot, 2001). Within the latter camp, two major approaches have been advanced. The first considers numerals as specifiers of a functional head ccommanding the NP in Slavic languages (e.g., Bailyn, 2004; Franks, 1994) and Indo-European languages (e.g., Kayne, 2010; Witkoś \& Dziubała-Szrejbrowska, 2018). The second treats numerals as heads that directly project numeral phrases (labeled as CardP, \#P, or Card\#P) in Hebrew and Arabic (e.g., Borer, 2005; Shlonsky, 2004), Mandarin Chinese (e.g., He, 2015), and Russian (e.g., Asinari, 2019). In some languages (such as Estonian), a combination of both approaches is argued to coexist (see, e.g., Norris, 2018). These two approaches can be represented as follows (Danon, 2012:1285):

1) a.

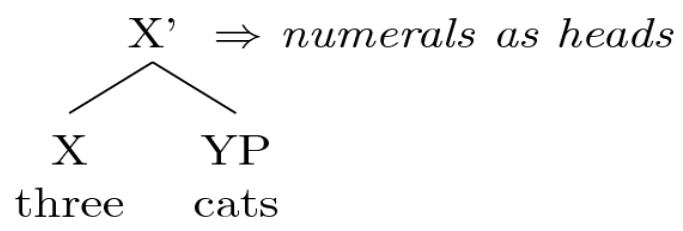

b.

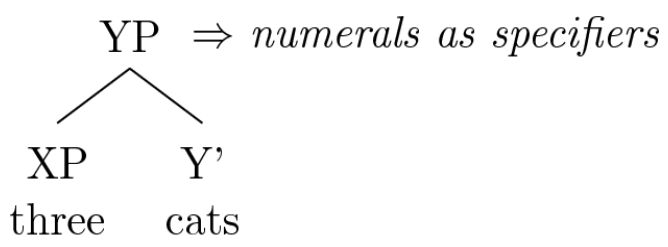


Neither of these structures are transparently suitable for Arabic, as they do not immediately provide an account for the characteristics and peculiarities of Arabic NNCs, because numerals do not have a uniform, consistent syntactic behavior with respect to word order, case assignment, and agreement for gender and number. That is, whether Arabic numerals are analyzed as heads that select the counted noun as a complement in (1a), or they occupy a specifier position of the counted noun in (1b) does not explain their diverse characteristics, some of which are illustrated in (2a-d). Notice that in (2a,b), although ' 100 ' and ' 30 ' require the counted noun to be singular, they assign genitive and accusative cases, respectively. In $(2 \mathrm{c}, \mathrm{d})$ ' 3 ' and ' 13 ', in contrast with ' 100 ' and ' 30 ', show gender polarity with the counted noun. Additionally, ' 3 ' requires the counted noun to be plural and genitive whereas ' 13 ' requires a singular and accusative enumerated noun:
2)

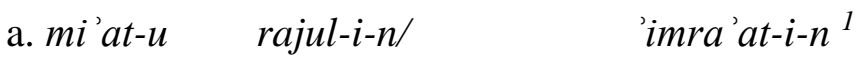
hundred-NOM man.MASC-GEN-N woman.FEM-GEN-N
'one hundred men/women'

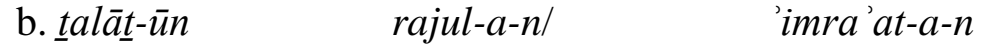
three-PL.NOM man.MASC-ACC-N/ woman.FEM-ACC-N
'thirty men'

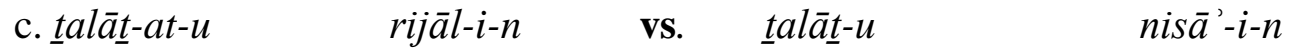

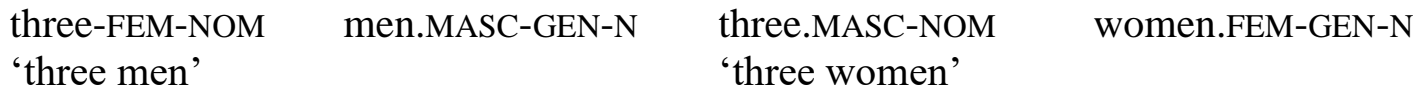

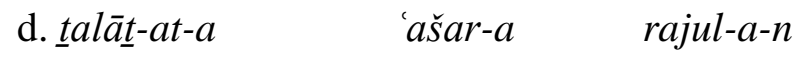
three-FEM-ACC ten.MASC-ACC man.MASC-ACC-N
'thirteen men came to me.'

The general difficulty of accounting for inconsistent requirements of enumerated DPs is related to the fact that previous studies overlook the internal structure of complex numerals. See, Ionin \& Matushansky, 2018, for an overview. In this paper, we address the latter and apply the results to the more general problem of how numerals related to their nouns. The resulting analyses also appears to shed light on the correlation between mathematics and linguistics as two inseparable domains of investigation in NNCs.

Briefly stated, we show that simple cardinals (e.g., 1-10) are quantifiers (Qs), which provide the genitive case on an enumerated noun and unifies the lexical category of all simple cardinals including ' 1 ' and ' 2 '. Compound numerals (e.g., '13') are analyzed as an unordered set $\{\mathrm{N}, \mathrm{N}\}$ mediated by Add\# 'additive number' head which linearizes and breaks the symmetry of $\{\mathrm{N}, \mathrm{N}\}$ and assigns the accusative case to both digits. Complex numerals (e.g., '12') are argued to involve another type of Num head (i.e., Multi\# 'multiplicative number') which requires its complement to be specified for gender, hence, contra other types of numerals, multiplicative cardinals do not show gender polarity. Similar to compound numerals, the prenominal position

\footnotetext{
${ }^{1}$ We use the following abbreviations: ACC: accusative; FEM: feminine; GEN: genitive; N: nunation (indefinite article); MASC: masculine; NOM: nominative; PL: plural; SG: singular. 1, 2, 3: first, second, third person, respectively. In the transliteration, the dot under the letter indicates that the sound is emphatic and pharyngealized; [t]], [ḍ], and [s] are the emphatic counterparts of [t], [d], and [s], respectively (for an overview of emphatic coronals, see, AlBataineh 2019).
} 
of complex cardinals triggers the change of plurality, definiteness, and case of the counted noun because the structure is headed by an $\mathrm{Ra}$ 'restrictive accusative' head that requires the movement of the numeral to its specifier position and the assignment of the accusative case to its complement. For patterns of gender polarity, the paper argues that this is a morphological process that applies to all simple cardinals unless other lexical or morphological processes block it. All simple cardinals enter the derivation with unvalued reverse gender agreement feature [U-RG], which requires the numeral to have an opposite gender feature when associated with the counted noun which has already valued gender feature. This claim finds support in the syntactic behavior of other compound numerals, which require only the first digit to disagree with the counted noun and complex numerals which do not involve gender polarity.

The structure of the paper is as follows: section 2 provides an overview of Arabic NNCs and the peculiarities involved in the syntactic properties of numerals related to case assignment, word order, and agreement for gender and number. Section 3 reflects on the previous studies on NNCs in Hebrew and Arabic and outlines the new approach adopted in this paper and explains the syntax of Arabic NNCs in depth, accounting for the syntactic behavior of simplex, compound, and complex numerals, respectively. Section 4 discusses the lexical category of 'one' and 'two' and the internal structure of the dual marker. Section 5 considers the theoretical implications of this approach.

\section{NNCs in Arabic}

As observed by Cantarino (1976:361), "a special difficulty encountered in the correct understanding of the numerals in Arabic is found in their peculiar agreement with their objects", a view shared by other scholars (e.g., Cowan, 1958:182; Haywood \& Nahmad, 1965:301; Kouloughli, 1994:121; Ryding, 2005:329). The complexity and challenge of the Arabic numeral system involves, in addition to anomalies of gender and number agreement, other peculiarities related to case assignment and word order. This section provides an overview of Arabic numerals based on their type, namely, simplex (i.e., 1-10), compound (i.e., 11-19) and complex (i.e., the remaining higher numerals).

Simplex numerals can be classified into two groups according to their syntactic behavior. The first group includes the adjective-like numerals, viz., waḥid 'one' and 'itnān 'two' which are shown in the literature to occur only post-nominally and to agree with the numerated noun in definiteness, case, and gender, as exemplified in (3a,b):

\begin{tabular}{|c|c|c|c|c|}
\hline $\begin{array}{l}\text { a. rajul-u-n wāhi } \\
\text { man-NOM-N one.N } \\
\text { 'one man' }\end{array}$ & $\begin{array}{l}u-n \\
\text { ASC-NOM-N }\end{array}$ & VS. & $\begin{array}{l}\text { 'imra'at-u-n } \\
\text { woman-NOM-N } \\
\text { 'one woman' }\end{array}$ & $\begin{array}{l}\text { wāhid-at-u- } n \\
\text { one-FEM-NOM-N }\end{array}$ \\
\hline $\begin{array}{l}\text { b. al-rajul- } \bar{a}-n \\
\text { the-man-DUAL-N } \\
\text { 'two men' }\end{array}$ & $\begin{array}{l}\text { al-'itn- } \bar{a}-n \\
\text { the-two.FEM-- }\end{array}$ & $\begin{array}{c}\text { vS. } \\
\text { DUAL-N }\end{array}$ & $\begin{array}{l}\text { 'imra'at- } \bar{a}-n \\
\text { Woman-DUAL-N } \\
\text { 'two women' }\end{array}$ & 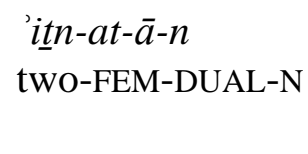 \\
\hline
\end{tabular}

The second group includes the noun-like numerals (3-10) which have three main characteristics. First, they are followed by the counted noun which has to be in the genitive plural form. Second, they show reverse gender agreement 'gender polarity', that is, the numeral takes the masculine marker when defining a feminine noun, and vice versa, as exemplified in (4a). The inverted 
gender agreement is determined by the gender of the singular form of the enumerated noun rather than by the gender of the plural form as in cases involving broken plurals of inanimate objects, notice that in (4b) kitab 'book' is masculine, but kutub 'books' is feminine. Third, whereas the counted noun can be definite or indefinite, the numerals can have neither the definite article alnor the indefinite article $-n(4 \mathrm{c})$.

4)
a. $\underline{\text { talät}}-$ at $\quad$ rijāl-i-n three-FEM men-GEN-N
'three men'
vS. talāt
$n i s \bar{a}^{\prime}-i-n$
three.MASC women-GEN-N
'three women'
b. $\underline{\text { talăt}}$-at $\quad k u t u b-i-n \quad$ (Notice that the singular form kitab 'book' is masculine.) three-FEM books.FEM-N
'three books'

c. $(* a l)-\underline{t a l a ̄ t}-a t-u-(* n) \quad(a l)-k u t u b-i-n$

(*the)-three-FEM-NOM- $(* \mathrm{~N})($ the $)$-books.FEM-N

'the three books'

Unlike simplex numerals, compound numerals (11-19), formed of two parts, the first digit and 'ašar 'ten,' show three main peculiarities. First, except for '12', compound numerals are invariable in case, that is, they are always marked accusative (or accusative-like ${ }^{2}$ ) regardless of their role in the sentence, as demonstrated below, the NNC is assigned the accusative case rather than the nominative from $\mathrm{T}$ in (5a) or the genitive from the $\mathrm{P}$ in $(5 \mathrm{~b})$. Second, all compound numerals require the following counted noun to be singular and accusative. Third, regarding gender agreement, the two digits in the compound numeral show two opposite patterns; the first digit shows gender polarity, whereas the second digit 'ten' agrees with the counted noun.

5)
a. 'atā-nī
talāt-at-a
'ašar-a
rajul-a-n
came-me three-FEM-ACC
ten.MASC-ACC man-ACC-N

'thirteen men came to me.'
b. qara'-tu
ar-riwāyat-a fì
talāt-at-a
'ašar-a
yawm-a-n
read-I
the-novel-ACC in
three-FEM-ACC
ten-ACC
day-ACC-N

'I have read the novel in thirteen days.'

The multiples of ' 10 ' from ' 20 ' to ' 90 ' are formed of a numeral stem (2-9) attached to the masculine plural suffix $-\bar{\imath} n$ for genitive-accusative or $-\bar{u} n$ for the nominative. This group of numerals shows two major anomalies. First, they behave differently than other numerals in having a common gender, that is, they do not display any gender differences or distinctions, as exemplified in (6).

\footnotetext{
${ }^{2}$ According to traditional grammarians, the two digits are mabnī 'alā alfatih 'built on the accusative marker', that is, they always bear an accusative-like marker regardless of their position. This view which is not adopted by modern linguists (e.g., Cantarino, 1976; Cowan, 1958; Ryding, 2005) who consider the two digits are accusative, is rejected in this paper for the simple reason that there is no plausible justification why these digits are built this way although they are nominals and they are expected to have the default nominative case in structures of imperfect checking domains (e.g., Al-Bataineh, forthcoming).
} 
6)

Second, although these numerals seem morphosyntactically similar to other nouns with the

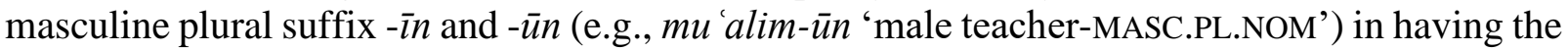

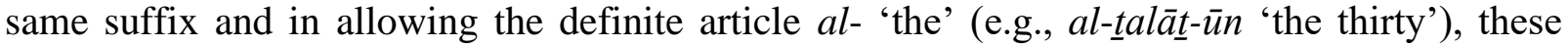
numerals show two peculiarities compared with similar plural nouns. First, the nasal $-n$ cannot be deleted when another noun follows the numeral, second, the following noun is marked accusative, rather than genitive, as in $(7 a, b)$ which represent two structures: Construct State and restrictive accusative, respectively:
7) a. mu'alim- $\bar{u}-\left(*_{n}\right)$ al-madrasat-i teacher-NOM-(N) the-school-GEN 'the teachers of the school'

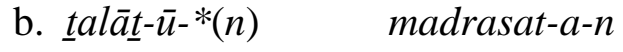 three-PL.NOM man-ACC-N 'thirty schools'

Moreover, these numerals can be pluralized with the feminine plural suffix $-\bar{a} t$ which attaches only to the genitive/accusative form (e.g., tala $\underline{a} \underline{-} \bar{\imath} n-\bar{a} t$ 'thirties,' cf. $\underline{t} a l \bar{a} \underline{t}-\bar{u} n$-* $\bar{a} t$ ) in sharp contrast with similar masculine plural nouns (e.g., mu 'alim-inn-*āt 'male teacher-MASC.PL.NOM-*FEM.PL).

The words for 'hundred', 'thousand', 'million', 'billion' fall into two patterns according to their gender, the feminine noun mi 'at 'hundred' and the other remaining masculine numerals, as evidenced in the gender polarity triggered when they are preceded by a numeral like talät 'three', as in $(8 \mathrm{a}, \mathrm{b})$.
8)
a. $\underline{\text { talăt}}-u \quad$ mi'at-i rajul-i-n three.MASC-NOM hundred-GEN man-GEN-N 'three hundred men'
b. $\underline{\text { talăt}}-a t-u \quad$ àlāf-i rajul-i-n three-FEM-NOM thousands-GEN man-GEN-N
'three hundred men'

Notice that these numerals have the same syntactic behavior regarding gender polarity, being assigned the genitive case and requiring the enumerated noun to be singular genitive (in contrast with all other numerals). Unlike other numerals within this set, $m i$ 'at 'hundred' shows a peculiar property of not being pluralized by the preceding numeral (notice that $m i$ 'at in (8a) is singular whereas ' $\bar{l} l \bar{a} f$ 'thousands' is the broken plural form of 'a $l f$ ). However, the given brief discussion of the Arabic numeral system is by no means comprehensive as other peculiarities will be highlighted and accounted for in the following relevant sections below.

\section{NNCs in Arabic revisited}

Bearing in mind the different peculiarities associated with NNCs in Arabic, the following subsections deal with the different syntactic properties of numerals according to their 
morphological types, that is, the complexity of their morphological formations which can be classified into simple, compound, and complex cardinals, to explain the complexities discussed above and other ones to be addressed below.

The main claim developed below is that enumerated DPs and complex numerals share a common structure (9), in which a Num head takes a complement with two components: a numeral and either another numeral or NP. There are four "flavors" of Num in Arabic: quantificational, additive, multiplicative, and "restricted accusative", each of which introduces its own semantic, selectional, Case-assigning and gender controlling characteristics. Num in Arabic always attracts a specifier, as well. We show that the structure in (9) reacts to each Num head in ways which ensure the actual surface forms of the full range of enumerated DPs.

9)

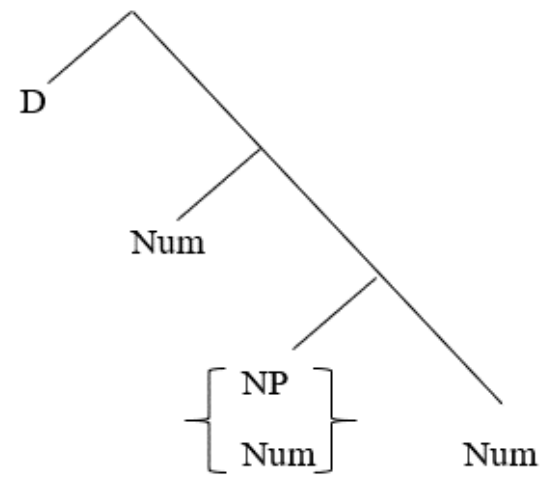

\subsection{Simple cardinals and the assignment of the genitive case}

Simple cardinals which are formed merely of one word without the addition of another numeral or an affix denoting multiplication include the numerals ('1-10') and the numerals denoting 'hundred', 'thousand', 'million' and 'billion'. These simple cardinals have a unified syntactic behavior that shows the consistency of their case assignment properties depending on their position with regard to the enumerated noun. These cardinals are subject to considerable attention from both classical grammarians (e.g., Al-Ansari, 1991; Al-Mubarrad, 1994; Aqeel, 1980; Sibawayh, 1988; Ya'īsh, 2001) and generative linguists (Alqarni, 2015; Alqassas, 2017; Borer, 2005; Danon, 2009, 2012; Marcin, 2016; Shlonsky, 2004).

Of course, Hebrew displays significant syntactic characteristics with Arabic, and simple cardinals in both languages have been argued to be either adjectives or nouns. Borer (2005:196) maintains that except for the post-nominal 'exad 'one' that behaves like attributive adjectives, all other cardinals are nouns that head a functional projection (i.e., \#P) within the extended projection of the enumerated noun. This view is adopted by other scholars (e.g., Danon, 2012; Shlonsky, 2004) to account for the difference between adjective-like numerals (Hebrew 'exad 'one' and Arabic wăhid 'one' and 'itnān 'two'), on the one hand, and other cardinals on the other. Although this generalization seems to account for two phenomena, viz., the absence of agreement in gender, number and definiteness between the noun-like numeral and the counted noun, and the pre-nominal position of the numerals, it fails in other respects. First, it wrongly predicts that numerals always assign the genitive case to the enumerated nouns. Numerals which head the \#P can assign the accusative case, as indicated in the previous section. Second, this 
differentiation cannot explain why some simple numerals like ' 3 ' require a plural counted noun, whereas other numerals like ' 100 ' require a singular counted noun. Thirdly, it implies that NNCs are syntactically equivalent to Construct States (CSs), as claimed and exemplified, for example, by Shlonsky (2004:1491, see also Danon, 2012:1283-1284, Borer, 2005:213-214):
10) a. $\underline{t}$ alāt $\underline{t}-u$
șuhuf-i-n
three.MASC
newspapers-GEN-N
'three newspapers'
b. $d \bar{a} r-u \quad$ ar-rajul-i
apartment.MASC the-man-GEN
'the man's apartment'

Although in both NNCs and CSs in $(10 \mathrm{a}, \mathrm{b})$ the numeral 'three' and the noun 'apartment' assign the genitive case to the following noun, they constitute two quite different structures for several reasons. First, in CSs, the head noun enters a semantic relation with the complement noun of either possession such as (10b) in which the head noun $d \bar{a} r$ 'apartment' is possessed by the complement noun rajul 'man' with the meaning of 'the man has an apartment', or a relation of origin or formation to denote 'made of/from' such as (11) below:

\section{1) kātam-u hadīd-i-n ring-NOM iron-GEN-N 'iron ring= a ring made of iron'}

According to traditional Arab grammarians, these two relations are triggered by the presence of the obligatorily covert prepositions $l i$ - 'of' and $\min$ 'from', respectively, which covertly exist between the head noun and the complement noun. The second reason is that in NNCs the enumerated noun is obligatory plural, as evidenced in the plural form of suhuf 'newspapers' following 'three' in (10a). This requirement does not exist in the complement noun in CSs, as can be seen in the singular form of rajul 'man' in (10b) and hadid 'iron' in (11). Third, whereas in CSs the head noun cannot be headed by the definite article al- 'the' in both Modern Standard Arabic and colloquial varieties, in NNCs the numeral can be headed by the definite article al'the' in colloquial varieties, as in (12) from Jordanian Arabic.

\section{2) al-talāt $\quad$ șuhuf the-three newspapers \\ 'the three newspapers'}

Given these differences, the NNCs and CSs should be distinct structures and the genitive case should be assigned to the complement noun with different syntactic mechanisms. In CSs, the abstract DGEN c-commanding the head noun assigns genitive case to the following noun (e.g., Ritter, 1992) ${ }^{3}$, but in NNCs a distinct functional head should provide the genitive case. (This functional head has syntactic properties different from that with compound and complex cardinals which carries the accusative case, as shown in subsequent sections.)

Our proposal is that simple cardinals originate together (in the base) with the enumerated noun, either as categorial adjectives or as nominals. The latter have the same syntactic characteristics as quantifiers (Qs) because they raise to the same position as other Qs such as kull

\footnotetext{
${ }^{3}$ Another syntactic approach which might account for the genitive case on the second nominal in CSs is to assume the existence of a covert preposition that carries the genitive case, as suggested by traditional Arab grammarians.
} 
'all', ba 'd 'some', kila 'both' and 'ahad 'one'. This claim not only provides a straightforward account for the genitive case assignment but also explains the lexical category of simple cardinals (i.e., adjectives or nouns) in relation to their position pre- or post-nominally in a unified proposal, represented in $(13 a, b)$ (the internal structure of NP in (13a) is simplified. For specific proposals on the detailed syntax of adjectives, see, e.g., Alexiadou, 2014; Cinque, 2010; Valois, 2006):

13) a.

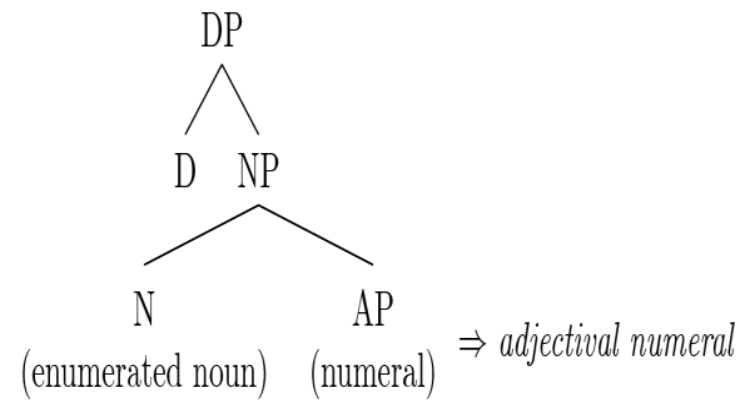

b.
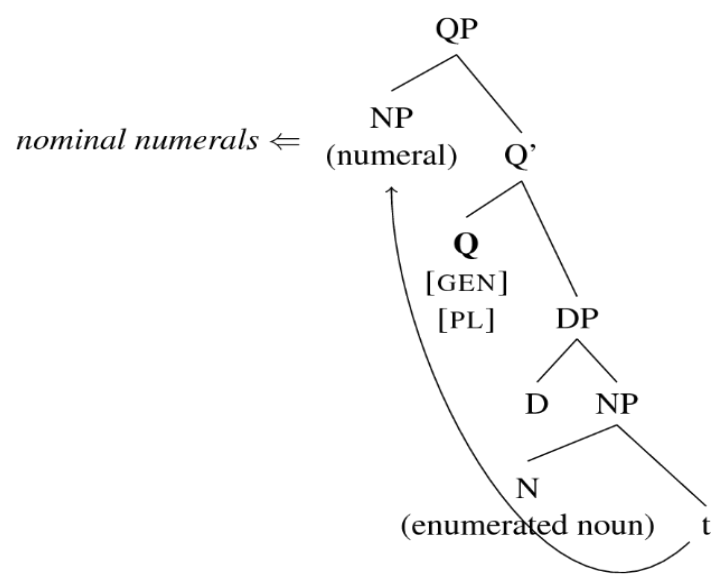

The contrast between nominal and adjectival cardinals in (14a-c) is illustrative. Notice that the genitive case assigned to the enumerated noun in the presence of a nominal cardinal whereas the nominative case is shared between the adjectival numeral and the noun in each of the following:

14) a. $\underline{\text { talāt}} \underline{-}-a t-u$
three-FEM-NOM
'three men'

b. $m i{ }^{\prime} a t-u \quad$ rajul-i-n

hundred-NOM man-GEN-N

'one hundred men'

c. 'alf-u rajul-i-n

thousand-NOM man-GEN-N

'one thousand men'

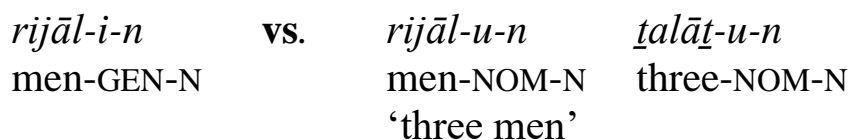

vs. rijāl-u-n mi'at-u-n

men-NOM-N hundred-NOM-N

'one hundred men'

vs. rijāl-u-n 'alf-u-n

men-NOM-N thousand-NOM-N

'one thousand men'

The case assigned on both the numeral and the enumerated noun is determined by the syntactic configurations they occur in. As represented schematically in the derivations (13a,b) above, the numeral can be an adjective; thus, it shares the same morphological case of the noun it associates with, that is, the numeral and the noun are c-commanded by the same D that "is specified for [...] a case feature that is valued from outside" (Ouhalla, 2013: 329). This syntactic mechanism for case assignment is not available when the numeral is a nominal expression that occupies a higher position than the enumerated noun (i.e., spec-QP). The derivation of the numeral in a prenominal position shows three features prevalent in all simple cardinals. First, the $\mathrm{Q}$ triggers the movement of the numeral, rather than the enumerated noun, since the former 
is the only one with properties denoting quantification (i.e., cardinality). Second, the enumerated noun is assigned only the genitive case from the Q (rather than from Dgen as assumed in the literature, for reasons highlighted above), as predicted from the syntactic behavior of all Arabic Qs. Agreeing with Khalaf (2019:17), "the case mismatch between the quantifier and the DP follows from the fact that the quantifier values its case features via Agree with an outside case probe [...] while the DP [...] is assigned genitive case via Agree with the quantifier." Third, both the $\mathrm{D}$ and the $\mathrm{Q}$ can be overt or covert simultaneously, that is, the presence of the overt $\mathrm{D}-n$ requires the $\mathrm{Q}$ to be morphologically realized as $\mathrm{min}$ 'of', and vice versa, as the contrast between (15a) and (15b) shows.

15) a. Nominal numerals with covert $D$

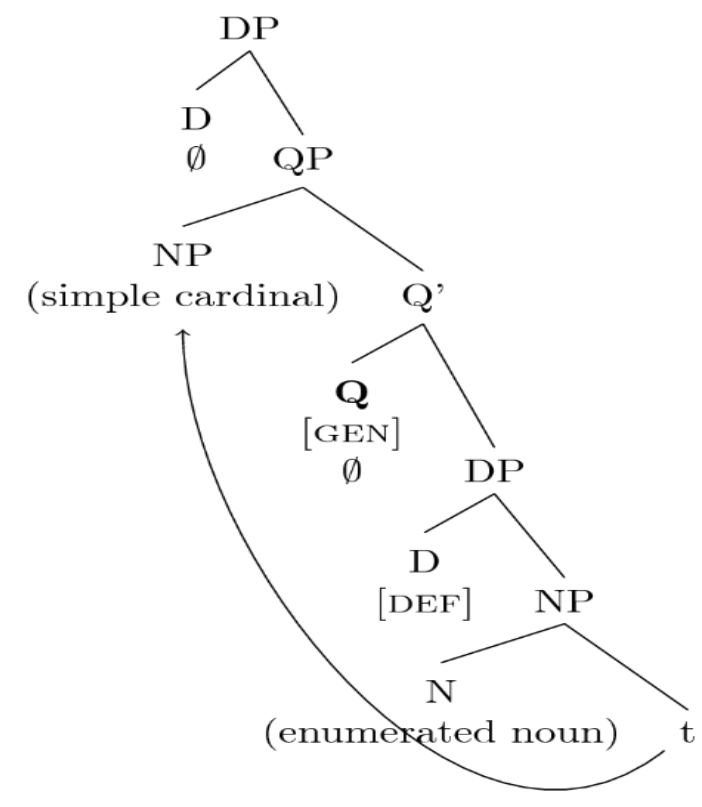

b. Nominal numerals with overt D

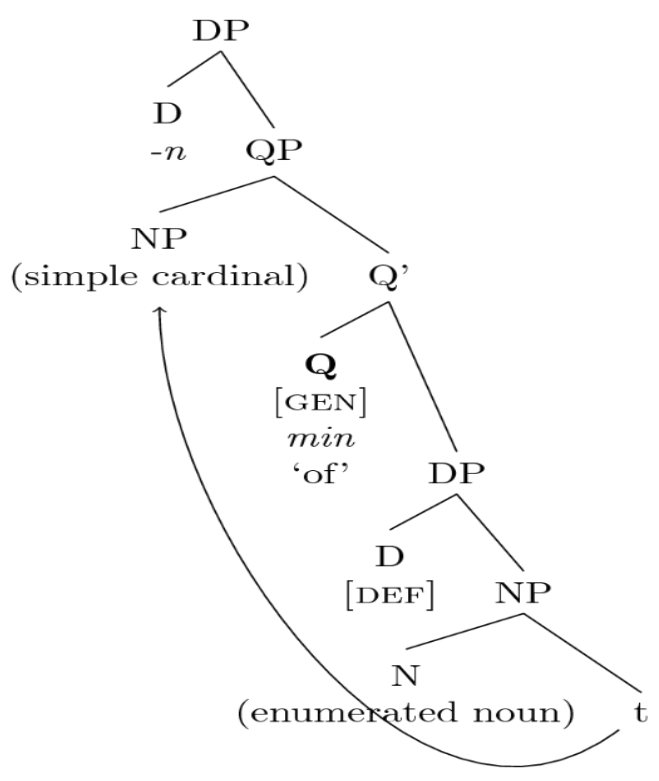

To illustrate, let us begin with the cardinal 'one', demonstrated as an adjective in (16a) and a noun in $(16 \mathrm{~b}, \mathrm{c})$. Notice that 'one' in postnominal position shares the same nominative case with the noun rajul 'man' due to the spread of the [NOM-case] feature from D to both constituents. This case match is not possible once the numeral occurs prenominally in (16b,c) because 'one' is marked the nominative case from outside while the enumerated noun is marked genitive via Agree with the Q. These facts are represented in the derivations (17a-c), respectively.

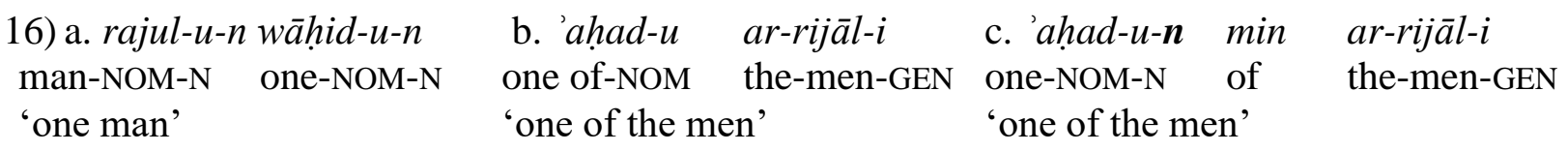


17) a. Adjectival 'one'

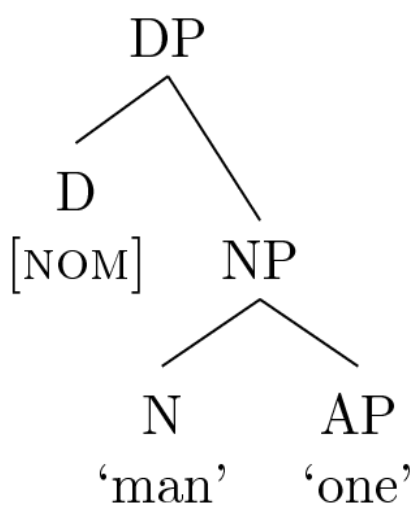

b. $\mathrm{N}$ 'one' with covert $\mathrm{D}$
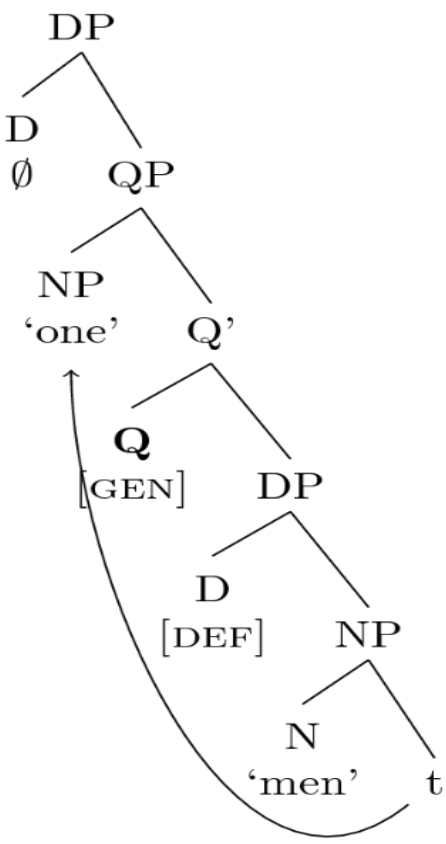

c. N 'one' with overt D

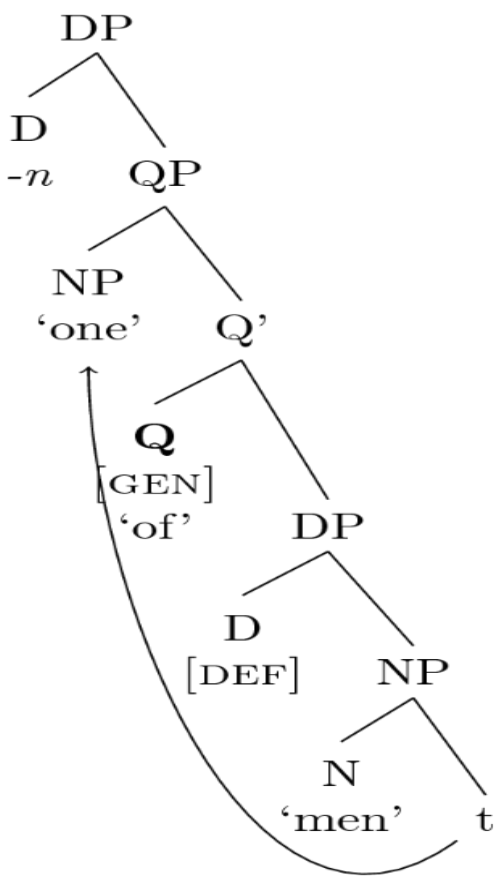

In addition to case (mis)match and the consistency between $\mathrm{D}$ and $\mathrm{Q}$ regarding morphological realization (i.e., covertness vs., overtness), notice that pre- and post-nominal 'one' do not have the same form, that is, the adjectival 'one' is wähid whereas the nominal 'one' is 'ahad, a phenomenon is also found in NNCs including 'two' (in addition to case (mis)match and overtness consistency between D and Q), as can be seen in (18a-c):

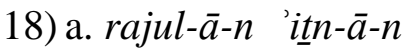
b. kila
ar-räjul-ay-n
c. kull-u-n min ar-räjul-ay-n

man-DL.NOM-N two-NOM-N both.NOM the-MAN- DL.GEN-N each-NOM-N of the-man-DL.GEN-N 'two men' 'both men' 'both of the two men'

The Q 'two' can be both singular and dual at the same time, as evidenced in the different number agreement between it and the AP mujtahid 'hardworking' in the predicate position of the following nominal sentence, which indicates that kilā can refer to either each or both of the men, simultaneously:
19) kilā
ar-rājul-ay-n
mujtahid-u-n /
mujtahid- $\overline{\boldsymbol{a}}-n$
both
the-man-DUAL.GEN-N hardworking-SG.NOM-N /
hardworking-DL.NOM-N

The other simple cardinals show the same syntactic patterns, as evidenced in the grammaticality of substituting them with the Q counterparts. Notice that 'three' behaves the same as ba 'd 'some' in requiring its complement to be a plural genitive noun in (20a) and 'hundred' and 'thousand' are syntactically equivalent to kull 'every' in requiring a singular, rather than plural, genitive noun, in (20b).
20) a. $\underline{t}$ alatat-at-u/ three-FEM-NOM/
ba dẹ-u
ar-rijāl-i 'three/ some men' 


$\begin{array}{lll}\text { b. } m i \text { 'at-u/ 'alf- } u / & \text { kull-u } & \text { rajul-i-n } \\ \text { hundred-NOM thousand-NOM/ } & \text { every-NOM } & \text { man-GEN-N } \\ \text { 'one hundred/ thousand men/ every man' } & \end{array}$

The last issue that needs to be accounted for in this approach concerns gender polarity, which exists in NNCs including the numerals ' $3-10$ ', but not other simple cardinals. Alqassas (2017) discusses this issue in-depth and argues that gender anti-agreement is caused by a morphological deletion process which is triggered by the feminine morpheme of the enumerated noun, that is, the feminine morpheme of the numeral is deleted only if the enumerated noun is feminine. This process affects only the numerals ' $3-10$ ' since they are underlyingly feminine, in contrast with other cardinals that do not have a default [FEM] feature. To support this argument, Alqassas (2017:4-5) indicates that ' $3-10$ ' and '100' are feminine (i) when they are used without a counted noun (e.g., talät-at 'three-FEM', 'arba'-at 'four-FEM', kams-at 'five-FEM', etc.,), and (ii) when they have partitive interpretation (e.g., 'ašarāt 'tens of', mi' $\overline{\boldsymbol{a}} \boldsymbol{t}$ 'hundreds of').

But Alqassas' arguments fail on two grounds. First, the multiplicative counterparts of these numerals (i.e., 20, 30-90) are formed by attaching the masculine, rather than the feminine,

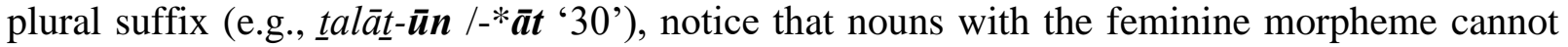

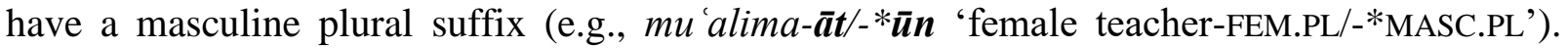
Even if we assume that the plural suffix in these numerals is not an actual plural suffix, but a noun meaning 'ten', we end up with an unanswered question, viz., why both the feminine words ' 3 ' and ' 10' in '30', for example, change to masculine forms (i.e., talātūn = talāt '3.MASC' and -ün'10.MASC'), rather than applying the deletion process and have gender polarity between them (i.e., *talāt-at-ūn '3-FEM-10.MASC' or *talāt-ät '3.MASC-10.FEM'). Second, if gender polarity is triggered by the underlying feminine morpheme in the numerals 3-10, it is not clear why other feminine numerals like ' 100 ' do not have the same process.

Contra Alqassas (2017), we, therefore, conclude that gender polarity is a morphological process that applies to all simple nominal cardinals unless other lexical or morphological processes block it. ' 1 ' and ' 2 ' show agreement with the counted noun because they are selected from the lexicon with a gender value already determined and which cannot, therefore, disagree with the associated noun. The nominal 'ahad 'one.MASC' has the feminine counterpart 'ihda 'one.FEM'. We notice that the feminine form is not formed by adding the regular feminine marker -at to 'ahad (*'ahad-at), rather it has a different form with $-\bar{a}$ which cannot be deleted for morphological reasons. It is noteworthy that feminine words ending with $-\bar{a}$ preserve this marker

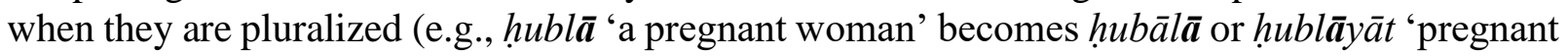
women'), in contrast with the feminine marker -at which must be deleted in the case of pluralization (e.g., jifnat 'eyelid.FEM' becomes jifan 'eyelids', muslimat 'muslim.FEM' becomes muslimāt not *muslimatāt). The numeral 'itnān 'two.MASC' has the feminine form 'itnatān 'two.FEM'. The feminine-like marker - at is also not an actual feminine marker because adding the feminine marker requires its attachment to the singular form of the word, and since ' 2 ' does not have a singular form of its own, the feminine marker is not added to the singular, but it is formed by attachment to the bound root 'itn with the result of two bound morphemes that cannot stand as a word (* itnat) without the dual marker. This process is similar perhaps to nouns belonging to pluralia tantum (e.g., English spectacles, trousers, scissors, etc., which cannot be said to have a singular feminine or masculine form).

Other simple nominal cardinals enter the derivation with unvalued reverse gender agreement feature [U-RG], which requires the numeral to have an opposite gender feature when 
associated with the counted noun which has an inherently valued gender feature. (This conclusion will find support in the syntactic behavior of other compound numerals, which require only the first digit to disagree with the counted noun and complex numerals which do not involve gender polarity, as explained in the following sections.)

\subsection{Compound cardinals and the assignment of the accusative case}

Except for '12', compound numerals '11-19' are formed from two parts, the first digit and 'ašar 'ten,' are invariable in case, that is, they are always marked accusative regardless of their role in the sentence. As for the gender agreement, the two digits show opposing patterns; the first digit shows gender polarity whereas the second digit 'ten' agrees with the counted noun. All compound numerals require the following counted noun to be indefinite, singular, and accusative, as demonstrated in (5a,b) above.

To account for these characteristics, let us consider the insertion of the definite article $a l$ 'the' and the indefinite article $-n$ on the numeral in $(21 \mathrm{a}, \mathrm{b})$, respectively.

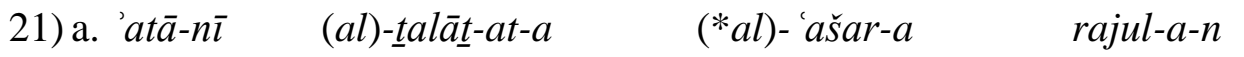

$$
\begin{aligned}
& \text { came-me the-three-FEM-ACC the-ten.MASC-ACC man-ACC-N } \\
& \text { 'thirteen men came to me.' }
\end{aligned}
$$

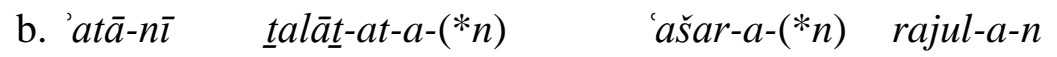

The ungrammaticality of attaching $-n$ to both 'three' and 'ten' indicates that these nominals cannot be regular DPs, and the attachment of -al only to the first digit indicates that both digits together form one NP that can be headed by a separate D. These facts can be accounted for based on the assumption that the two digits are Ns which enter the derivation as an unordered set $\{\mathrm{N}, \mathrm{N}\}$ in an exocentric, symmetric relationship; at this point, neither $\mathrm{N}$ can determine the formed syntactic category as they c-command each other (Chomsky 2007). The symmetric set needs to be in a hierarchical order or linearized to rescue the structure at PF. Since the meaning of the compound numeral is that of addition (i.e., $3+10=13$ ), we assume a functional Num head must ensure that interpretation. For clarity, we refer to this flavor of Num as Add\# 'additive number', a functional head which c-commands the unordered set and requires one of the two Ns to move to its specifier position. The digit with the lower value 'three' is the one which moves, which may be derived from the property of being the only digit which can attach to al- 'the', due to an unvalued [DEF] feature, as demonstrated in (22): 
22)

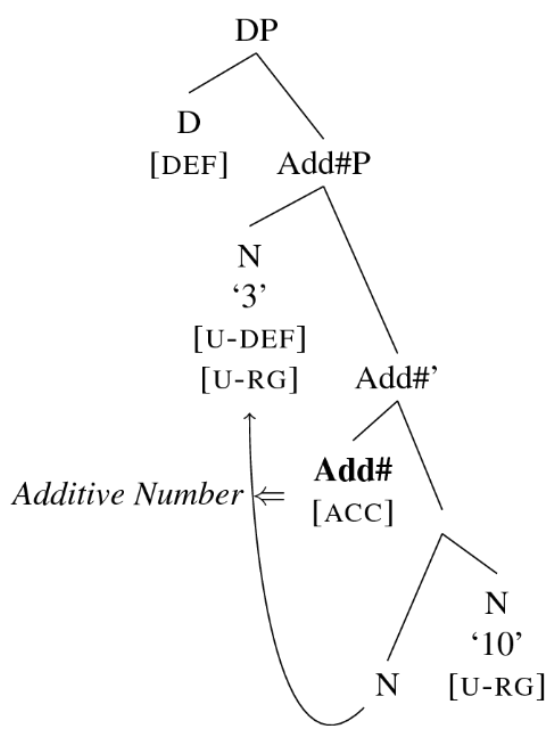

This representation explains the right word order in which the digit with the lower value must precede the other digit, and it provides the configuration which explains why both digits cannot receive the indefinite article $-n$, and why only the first digit allows the attachment of $a l$-.

External to the complex numeral, the larger DP is derived either by fronting the enumerated noun or by raising the numeral itself. (24) illustrates the DP 'thirteen men' in (23), in which the Ns ' 3 ' and ' 10 ' are assigned the accusative case by Add\# head, and the whole DP is assigned nominative case invisibly on D depending on its position as an adjective following the nominative 'men':

23) 'atā-nī ar-rijāl-u al-talāt-at-a 'ašar-a came-me the-men-NOM the-three-FEM-ACC ten.MASC-ACC 'thirteen men came to me.'

24)

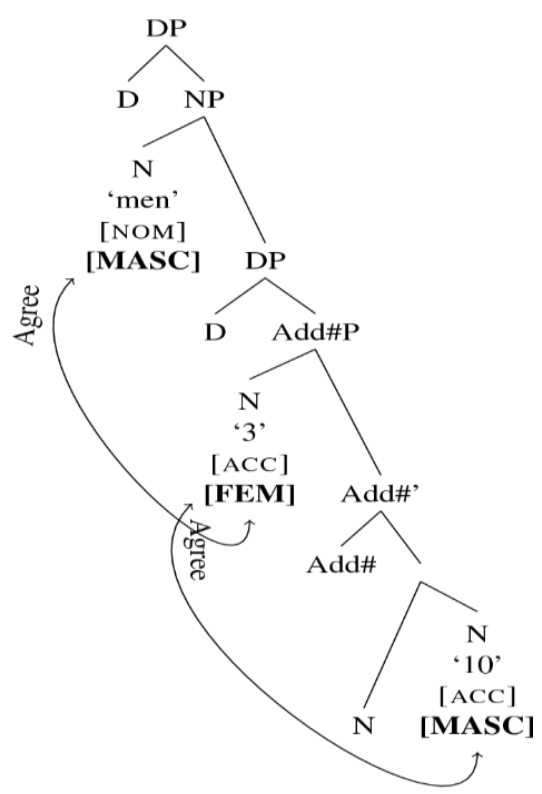


Moreover, this representation assumes that both digits have an unvalued reverse gender feature [U-RG] which must be valued by a higher $\mathrm{N}$ in the structure. The enumerated noun enters the derivation in a c-commanding position to value the [U-RG] features carried by ' 3 ' and ' 10 '. In (23), the counted noun is 'men', hence, it carries the valued [MASC] feature which enters in agreement relation with 'three' and makes it $\underline{t}$ ala $\underline{t}$-at with the feminine marker -at, and 'three' being higher than 'ten' agrees with it and makes it with the masculine marker, as the process of gender polarity requires each noun to have a reverse gender feature with the higher ccommanding noun. This analysis explains the gender polarity between the three Ns, case marking, and the absence of any effect of the compound numeral ' 13 ' on the counted N 'men'.

The other possibility is to have the numeral preceding the counted noun, and in this case, the counted noun becomes singular, indefinite, and accusative, as the counterpart of (23) shows:
25) 'atā-nì
al-talāt-at-a
'ašar-a
rajul-a-n
came-me the-three-FEM-ACC
ten.MASC-ACC man-ACC-N
'The thirteen men came to me.'

The NNC represents the construction tamyizz 'accusative of specification' or 'restrictive accusative' in which a nominal element limits or specifies the interpretation of another nominal element. In (25), the counted noun rajul 'man' specifies and limits the interpretation of the numeral ' 13 ', that is, 'men' specifies the entities counted by ' 13 ' ${ }^{4}$. In this construction, the counted noun does not get the accusative case directly from the numeral simply because the numeral is assigned nominative invisibly by virtue of its thematic role AGENT as the subject of the sentence; rather it is marked accusative by a functional Num head that triggers the movement of the numeral to a prenominal position. We label this head as $\mathrm{Ra}$ 'restrictive accusative' which merges with the moved DP numeral to form RaP, as in (26):

26)

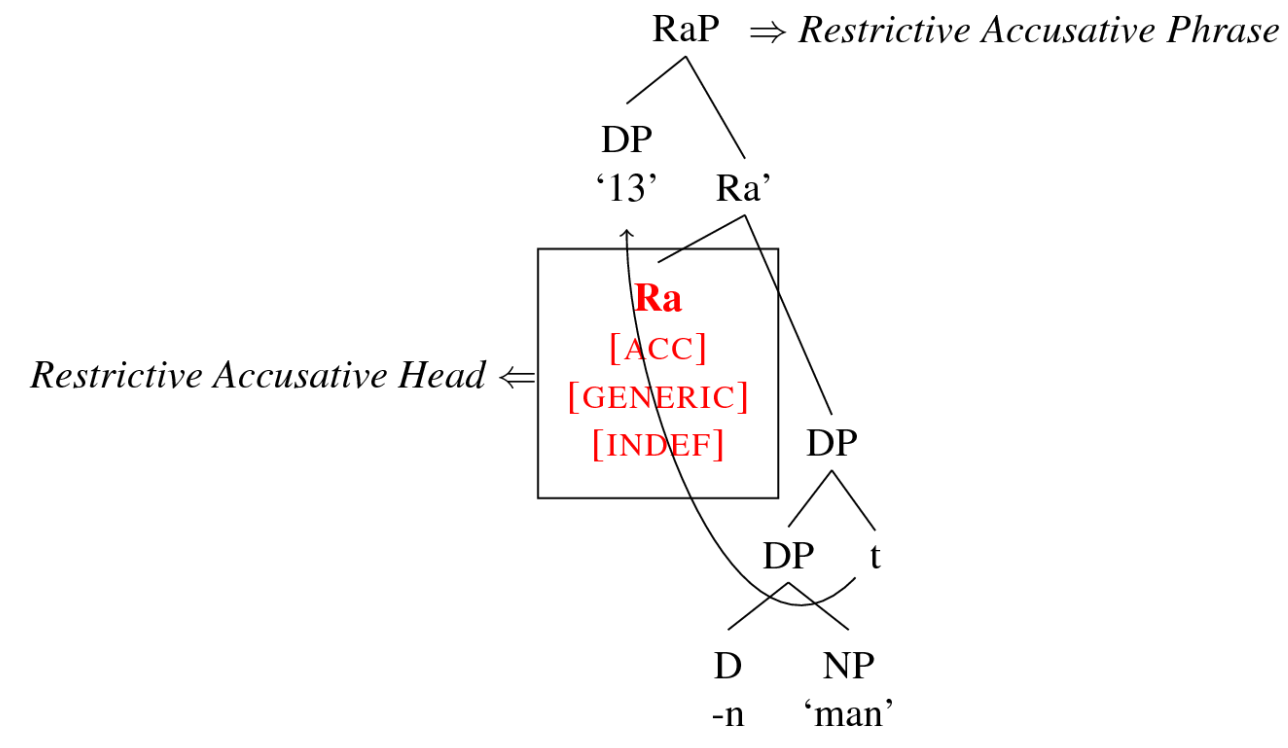

\footnotetext{
${ }^{4}$ tamyizz constructions discussed in this paper are related to Semitic languages, as they occur in Arabic (Ya'īsh, 2001)) and Hebrew (Meek, 1940, 1945) differently than in other languages such as Greek (Hahn, 1960) and Latin (Kirk, 1919)
} 
The Ra head carries the [ACC-case], [GENERIC], and [INDEF] feature which make the complement $\mathrm{N}$ accusative, generic, and indefinite; hence, the change from ar-rijāl- $u$ 'the-men-NOM' in (23) to rajul-a-n 'man.INDEF-ACC-N' in (25). The Ra head can be morphologically null, as in (25), or overt taking the form of the preposition $\mathrm{min}$ 'of' and behaving like a regular preposition in carrying the [GEN] case and not imposing any changes on its DP complement regarding genericity or plurality, as exemplified in (27):
27) 'atā-n̄̄
talāt-at-a
'ašar-a $\quad \min$
ar-rijāl-i
came-me three-FEM-ACC
ten.MASC-ACC of
the-men-GEN
'Thirteen of men came to me.'

This analysis not only explains the inflection of the counted noun but also clarifies the right syntactic configuration in which two identical units form one syntactic object, that is, the Ra head licenses and enables the connection of two DPs in Arabic to form one unit.

This pattern resembles other cases of tamyiz 'accusative of specification' constructions, as exemplified below. Notice the change of case assignment between the construct states and tamyiz constructions in (28a-c), respectively, due to the presence of the $\mathrm{D}-n$ in the latter:

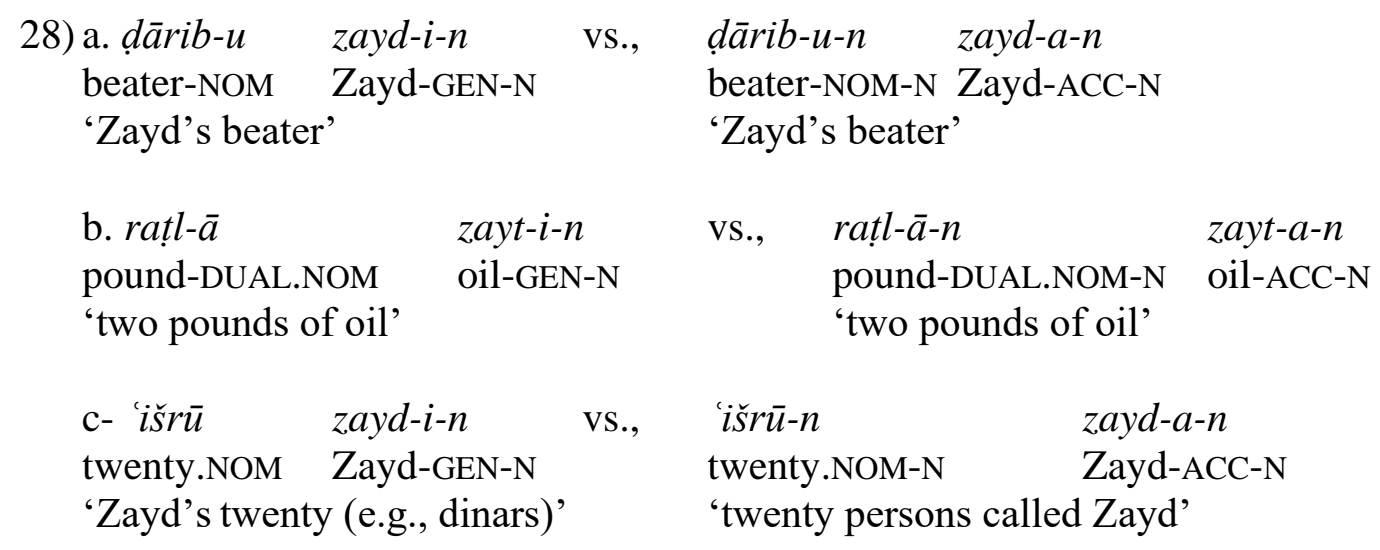

These examples show that while CSs are combinations of a $\mathrm{N}$ and a DP, tamyzz constructions are combinations of two DPs. Further support of the view of tamyiz as two DPs can be found in (29) in which the first DP is a CS, and the second is a regular DP, notice that CSs cannot combine more than two nominals whereas in tamy $\bar{z}$ three nominals may exist:

$$
\text { 29) } m i l \text { '-u al-'ard-i dahab-a-n }
$$

fullness-NOM the-earth-GEN gold-ACC-N

'the whole capacity of the earth in gold'

(Qurān: Al- 'imrān:91)

In both contexts, it appears that two Ns can be combined and have the accusative case, as in the compound numeral ' 13 ' above. This combination is not restricted to numerals, as compound nouns have the same behavior, as in (30a-c) (for more examples, see, e.g., Ya'īsh, 2001:143164):
30) a. 'ātī-ka
$\operatorname{mas} \bar{a}^{\prime}-a$
comeI-you.MASC.OB
morning-ACC
'I come to you everyday anytime.'
b. huwa jār-ī
bayt-a
bayt-a
he neighbor-my house-ACC house-ACC
'He is my next-door neighbor.'

wa yawm-a

yawm-a

evening-ACC and

day-ACC

day-ACC 

c. waqa 'a hāda
al-'amr-u bayn-a
bayn-a
happened this.MASC the-issue-NOM between-ACC between-ACC
'This issue has taken place in some in-between state'

The expressions șabāha masā'a 'morning evening', yawma yawma 'day day', bayta bayta 'house house', and bayna bayna 'between between' are similar to '13' in being a DP formed of two Ns which are marked accusative due to the presence of a functional head F (similar to Add\# above except it does not denote addition) that triggers the movement of one of the Ns to its specifier position, but unlike ' 13 ', they cannot be preceded by al- 'the' since they must be headed by a null $\mathrm{D}$.

To sum up the different types of DP constructions discussed above, the following representations illustrate Construct States, compound numerals, compound nouns, respectively, highlighting the morphological realization of $\mathrm{D}$ in each structure:

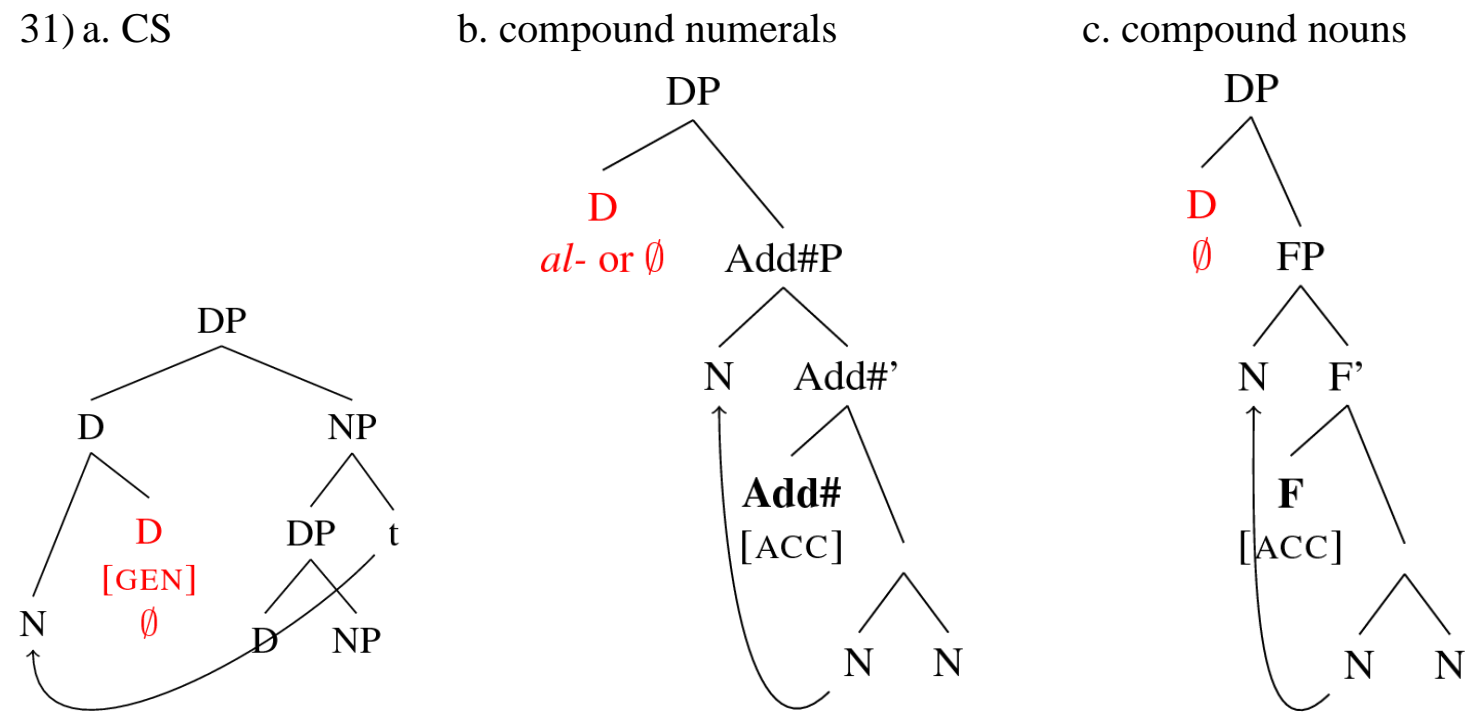

In (31a), the $\mathrm{N}$ moves to reach a position where it can be assigned case to avoid Case Filter, and the D assigns case to its complement DP. $(31 \mathrm{~b}, \mathrm{c})$ explain the two possibilities of connecting two Ns which can be headed by either $\varnothing$ or al- 'the' as in the numeral ' 13 ' or only $\varnothing$ as in the other forms exemplified in (30a-c). In both structures, the two Ns are assigned accusative by the functional head Add\# or F, respectively. In contrast, tamyiz constructions are formed of two DPs in two possible constructions. The first belongs to the connection of the numeral and an enumerated noun, as in (32a). The second is related to the combination of a CS and a DP, as in (32b), exemplified in (29) above. In both structures, the second DP is assigned accusative by Ra head which also requires its complement DP to be indefinite and generic. 
32) a. tamy $\bar{\imath}$ : compound numeral-counted noun

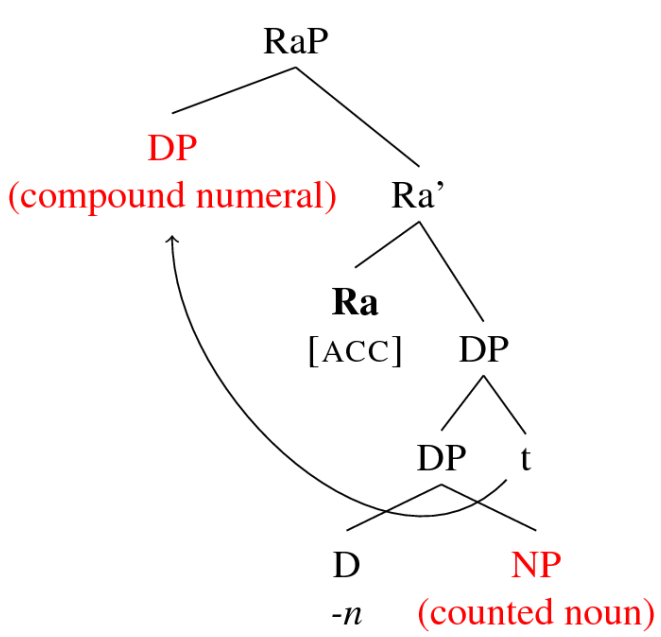

b. tamyīz: CS-DP

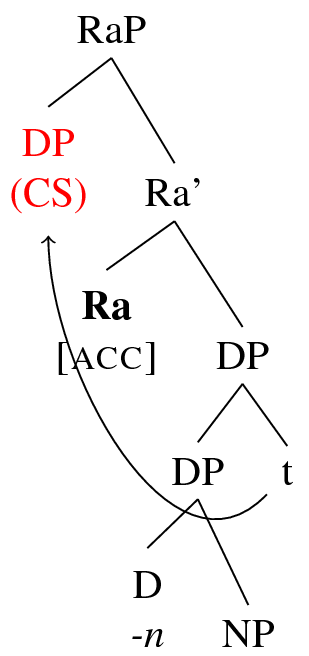

\subsection{Complex cardinals and the effect of affixal multiplicatives}

The complex cardinals are ' 12 ' and the multiples of ' 10 ' '20-90' which are basically formed of a numeral stem denoting '2-9' attached to a multiplicative suffix. ' 12 ' behaves exactly like other compound numerals ' $13-19$ ' discussed above except for two issues; the first digit shows case variation, and no gender polarity takes place, as exemplified in $(33 \mathrm{a}, \mathrm{b})$. Notice that ' 2 ' has two case endings $-y$ and $-a$ for accusative and nominative, respectively, and both digits have masculine morphology in agreement with 'man':

$$
\begin{aligned}
& \text { 33) a. ra'y-tu 'itna-y 'ašar-a rajul-a-n } \\
& \text { saw-1SG.SBJ 2.MASC-ACC 10.MASC-ACC man-ACC-N } \\
& \text { 'I saw } 12 \text { men.' }
\end{aligned}
$$
b. 'atā-n- $\bar{l}$
'itna-a
'ašar-a
rajul-a-n
came-NN-1SG.OBJ
2.MASC-NOM
10.MASC-ACC
man-ACC-N
' 12 men came to me.'

Case variation and the blocking of gender polarity with ' 12 ' do not pose a contradiction to the given arguments regarding compound numerals since ' 12 ' is not just the addition of ' 2 ' to ' 10 ' like other compound cardinals. ' 2 ' is composed of the root 'itn and three morphemes: the dual marker $-a$, the case marker $-y /-a$, and the nunation-like element $-n$. The $-n$ morpheme behaves like regular nunation in its deletion in CSs, but it cannot be omitted when al- 'the' exists (e.g., al-kitab- $\bar{a}-*(n)$ 'the-book-DUAL.NOM-*(N)') in contrast with singular forms which cannot allow both al- and $-n$ simultaneously (cf. al-kitab-u-(*n) 'the-book-NOM- $\left(*^{*} \mathrm{~N}\right)$ '). This idiosyncratic behavior indicates that the dual marker must contain the feature bundle [NUM, DEF], hence, the obligatory attachment of an element with the [INDEF] (i.e., $-n)$ before $a l$ - 'the' (cf., $(* a l)-k i t a b-\bar{a})$ (more details are given in section 4). The same arguments apply on '12' with the addendum that instead of attaching $-n$, the nominal ' 10 ' is required before ' 2 ' reaches a position where it can have $a l$-, that is, ' 10 ' satisfies the requirement of ' 2 ' to have [INDEF] feature before it is headed 
by the D al- (see also, Ya'īsh, 2001:16, for more supportive pieces of evidence related to the annexation of possessive bound suffixes).

Compare the forms $(34 a, b)$ :

34) a. ar-rijāl-u al- 'itna-a-*(n)

the-men-NOM the-2.MASC-NOM

'the 12 men'

b. ar-rijāl-u al-'itna-a-(*n) 'ašar-a

the-men-NOM the-2.MASC-NOM- $\left({ }^{*} \mathrm{~N}\right)$ 10.MASC-ACC

'the 12 men'

While the presence of $-n$ is obligatory in (34a), it is not allowed in (34b) because '10' occupies the same position of $-n$. That is, the form 'itna-a can be either 'itna-a-n or 'itna-a 'ašar-a but not 'itna-a-n 'ašar-a because both - $\boldsymbol{n}$ or 'ašar-a have the same syntactic function and position.

But the same cardinal also combines to form multiplicative complex numerals. Consider the derivation of (34b):

35)

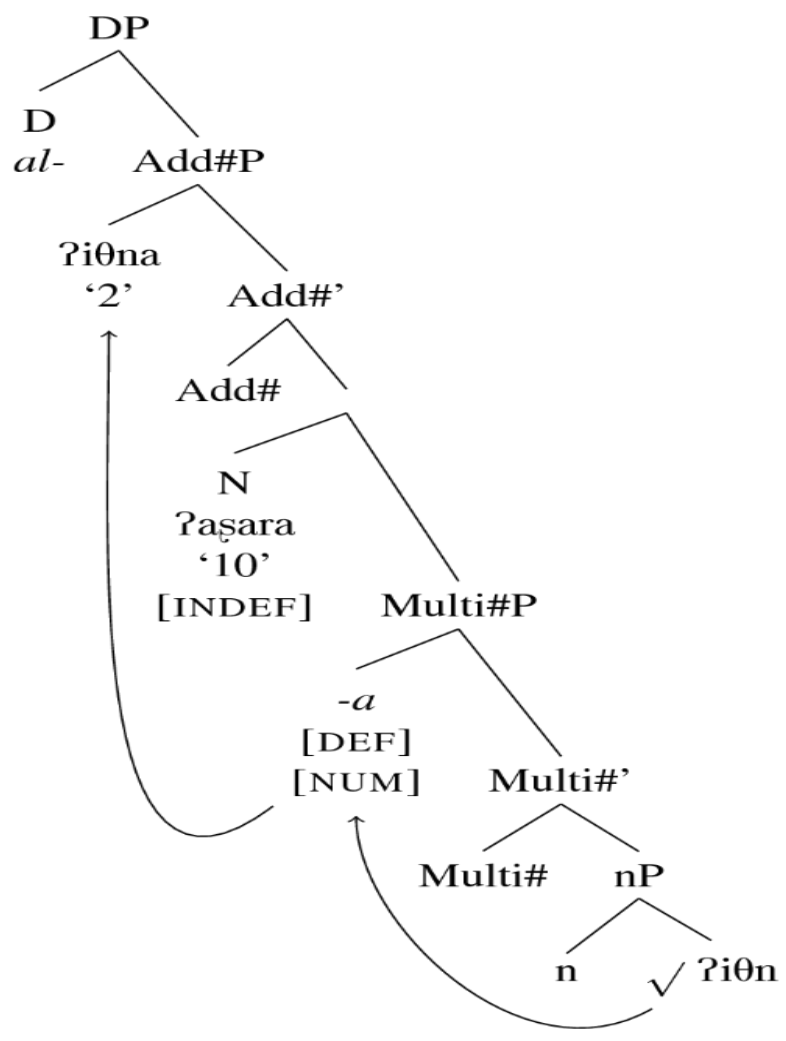

The root 'itn (which is the spell-out of $\sqrt{ } 1$ ) merges with the nominalizer head $\mathrm{n}$ to form $\mathrm{nP}$ which in turn merges with Multi\# (Num) head 'multiplicative number' which licenses the morpheme $a$ in its specifier position since the dual marker $-a$ denotes a multiplication of the same entity (e.g., two books= book x2). The Multi\#P merges with ' 10 ' in a symmetric relation to form an unordered set which is c-commanded by Add\# that requires the movement of the nominal 
denoting the lower value as in other similar derivations of compound numerals. '2' moves after it has the [INDEF] feature from ' 10 ' which must be indefinite as evidenced in its inability to be attached to al- 'the'. The formed DP is c-commanded by the DP 'the men' (the counted noun) which provides the nominative case to 'itna. Further movement of the formed Add\#P to prenominal position proceeds in the same way as other compound numerals, that is, to spec-RaP, and the plural counted noun becomes singular and accusative.

The given analysis can be supported by the attachment of the dual marker - $a$ to simple cardinals like 'hundred' or 'thousand' which must be followed by an indefinite $\mathrm{N}$ that occupies the same position of $-n$ to change the inherent definiteness of the dual marker. Notice in $(36 a, b)$ 'man' and 'thousand' following - $a$ must be indefinite:

36) a. $m i{ }^{\prime} a t-\bar{a} \quad$ I'alf- $\bar{a} \quad$ rajul-i-n $\quad$ *al-rajul-i

hundred-DUAL.NOM / thousand-DUAL.NOM man-GEN-N / $*$ the-man-GEN 'two hundred/ two thousand men'
b. $m i{ }^{\prime} a t-\bar{a}$
'alf-i-n
$/ * a l-$ ' $^{\prime}$ lf-i
hundred-DUAL.NOM thousand-GEN-N
/*the-thousand-GEN-N
'two hundred thousand'

In the analysis of ' 12 ', we conclude that the Multi\# requires its complement to be specified for gender, and this is the reason why gender polarity does not take place in NNCs denoting multiplication. This claim finds further support in the fact that simple multiplicative cardinals (e.g., '100', '1000', '1,000,000', etc.,) are specified for gender, in contrast with other simple cardinals (i.e., 3-10). The same phenomenon also exists in the multiples of 10 (i.e., 20-90) which are formed of a numeral stem '2-9' attached to the Multi\# - $n$ (i.e., the masculine plural suffix $\bar{i} n$ for genitive-accusative or $-\bar{u} n$ for the nominative). Notice in (37) that ' 30 ' does not display any gender differences or distinctions when associated with either 'men' or 'women'.

37) a. ar-rijāl-u / an-nis $\bar{a}^{\prime}-u \quad$ at $\underline{t}$ - $a l a \bar{t} \underline{-}-\bar{u} n$ the-men-NOM / the-women-NOM the-three-PL.MASC.NOM 'the thirty men/women'
b. at $\underline{t} \underline{t} a l \bar{a} \underline{t}-\bar{u} n$
rajul-a-n /'imra'at-a-n
the-three-PL.MASC.NOM
man-ACC-N / woman-ACC-N
'thirty men/women'

The multiplicative cardinal ' 30 ' does not change regardless of the gender of the counted noun, as evidenced in its attachment to the sound masculine plural suffix $-\bar{u} n$. This phenomenon indicates that ' 3 ' in ' 30 ' behaves like a masculine $\mathrm{N}$ such as mu 'alim 'male teacher' which is pluralized as mu 'alim- $\bar{u} n$ 'male teacher-PL.MASC.NOM'. To account for the syntax of '30' postand pre-nominally in $(37 \mathrm{a}, \mathrm{b})$, respectively, the following derivations are representative: 


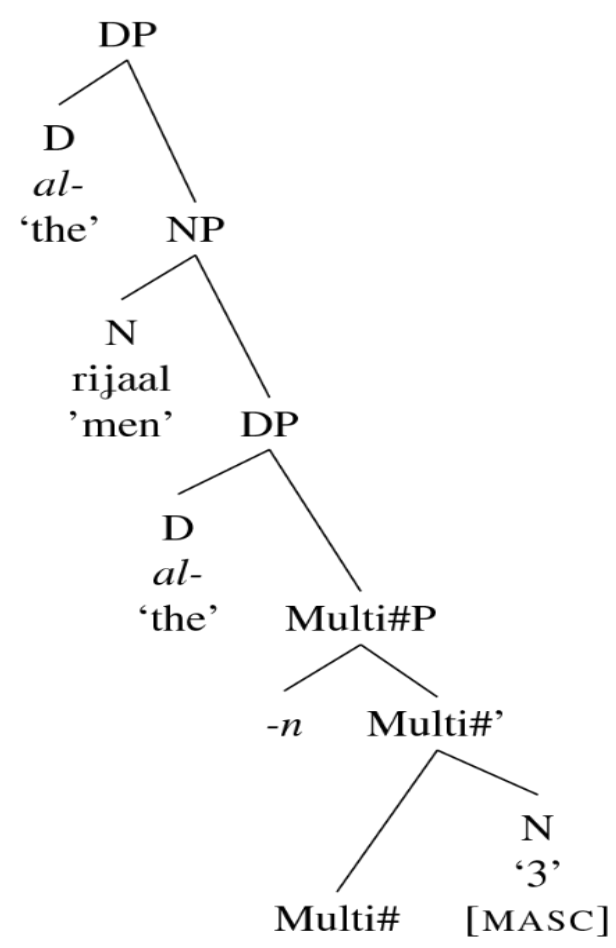

The N ' 3 ' enters the derivation specified for [MASC] gender as required by Multi\# to form Multi\#' which merges with $-n$ (i.e., an element denoting the multiplication of 10 , similar to the dual marker $-a(\mathrm{x} 2))$. The formed Multi\#P merges with $\mathrm{D}$ which values its case feature by Agree with the c-commanding D in ar-rijäl. Hence, the nominative case spreads on both the counted noun and the numeral. The prenominal position of ' 30 ' that triggers the change of plurality, definiteness, and case of the counted noun in (37b) can be straightforwardly accounted for in the light of the analysis given for compound numerals, as both constructions follow the same syntactic mechanisms, that is, the formed structure is headed by Ra head that requires the movement of the numeral to its spec position and the assignment of the accusative case to its complement, as in (39):

39)

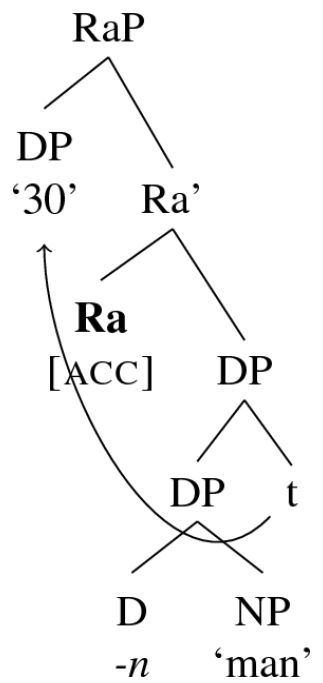


The numeral stem ' 3 ' is assumed to be masculine, rather than feminine, based on the fact that when this number is associated with a generic noun that refers to both males and females simultaneously, only the masculine form of ' 3 ' is used, as in (40):

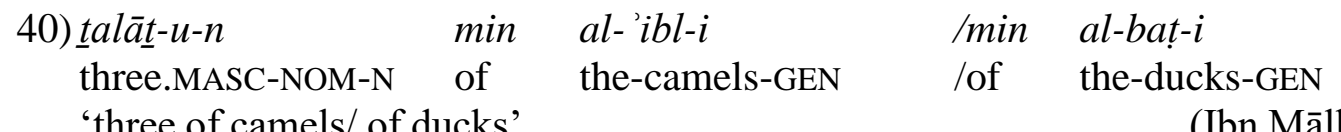

(Ibn Mālk, 1990:398)

As the numeral stem enters the derivation specified for [MASC] feature, and no gender polarity takes place with multiplicative numerals, the numeral stem attaches to the masculine plural suffix $-n$, rather than the feminine plural suffix $-\bar{a} t$. Another reason for ruling out the feminine suffix is that $-\bar{a} t$ cannot provide specific numeric value when it attaches to numerals (cf. 'ašar-āt 'tens', $m i$ '-àt 'hundreds', $\underline{t} a l \bar{a} \underline{t} \bar{\imath} n-\bar{a} t$ 'thirties', etc., ).

Further support of the suffix $-n$ as a multiplicative suffix can be found in the pronunciation of ' 20 ' which is 'išrūn rather than * 'ašaratūn. Agreeing with traditional grammarians (e.g., Ya' īsh, 2001:19), '20' begins with the stem 'išr denoting ' 2 ', equivalent to 'ith in ' 2 ' and ' 12 ' above, as evidenced in their equal phonological CVCC structure, more specifically, they have the sequence [Guttural], [I], [Coronal], and [Sonorant]. The use of the stem 'išr, rather than the free morpheme 'ašarat ' 10 ', supports the status of $-n$ as ' $\times 10$ ' because mathematically the attachment of 'išr to - $n$ ('2' -'x10') yields '20' but 'ašarat-n ('10' -'x10') yields 'one hundred'. Moreover, 'išr is used instead of 'itn because the latter cannot be utilized for numerals other than ' 2 ' as it is the root for mutannā 'dual noun', and the derivation of 'išr from 'ašarat is needed to highlight that ' 20 ' is a multiple of 10 .

\subsection{Other cardinals and the need for the conjunction $w a$ 'and'}

In the preceding sections, cardinals are divided into three groups (i.e., simplex, compound, and complex cardinals, respectively) depending on their morphological complexity and syntactic behavior. The different forms in the given groups raise the following questions: why do these groups include only a limited set of cardinals, and not other ones, that is, why are compound cardinals only from 11-19, what prevents the formation of ' 20 ' as 'ašara 'ašara ' 1010 ' in the same way ' 19 ' tis 'ata 'ašara '9 10' is formed, and why 'ašarat- $n$ cannot be a cardinal to denote to '100' and the different form mi' at is needed. The answer to these questions lies in the nature of the Num head whether it denotes addition (i.e., Add\#) or multiplication (i.e., Multi\#). The Num head cannot have a specifier and a complement of the same numeric value within the same formed DP, as it requires the digit with the lower value to move higher, and the DP cannot have more than two Num heads (i.e., two Add\#s or two Multi\#s or a combination of both) ccommanding its $\mathrm{N}$ as that would yield more mathematical processing within the same projection. We can state these assumptions in the following principle:

Each DP has one and only one Num head (regardless of its type) which specifies the numeric value of the $\mathrm{N}$ (whether it denotes cardinality or not).

In support of this principle, we argue that in additive compounds the DP has only one Add\# head that connects two digits unequal in their numeric value; hence, compounds include cardinals 1119 , but not 20. The same logic accounts for why to form ' 20 ' the DP requires a different type of Num head (i.e., the Multi\# head) which can derive cardinals from 20 up to 90, but not 100, as 
100 requires the multiplication of the same digit ' 10 ', and in this case, $m i$ ' at is used as a separate lexical entry. Furthermore, to form '300-900', mi'at behaves exactly like the multiplicative suffix $-n$, that is, it occupies the spec-Multi\#P (a multiplication takes place between the numerals 3-9 and $m i$ ' $\bar{t}$ to form '300-900' (e.g., talät mi' àt '3 100' '300'), it can attach to the cardinal 3-9 to form one word (e.g., talāt-mi 'àt '3-100' = '300'), and it does not change its form (i.e., it cannot be pluralized as expected from any $\mathrm{N}$ following 3-9).

However, the last lexical entry denoting cardinality in Classical Arabic is 'alf 'thousand' which cannot follow the same mathematical processes for other numerals as it requires two Multi\# heads to be formed (i.e., it is the multiplication of 10 three times, that is, $10 \times 10 \times 10=$ 1000), and since in each DP only one Num head exists, 'alf enters the derivation as a counted noun rather than a derivation of other numerals (the same reasoning applies to other higher borrowed numerals, e.g., malyūn 'million', bilyūn 'billion', and trilyūn 'trillion'), and that may indicate a correlation between mathematical processing and linguistic derivation. The given arguments concerning 'hundred' and 'thousand' account for the peculiarity in pluralizing 'thousand', but not 'hundred', as exemplified in (41a,b):

\begin{tabular}{|c|c|c|c|}
\hline $\begin{array}{l}\text { 41) a. } \underline{\text { tala } \underline{t}-u} \\
\text { three.MASC-NOM } \\
\text { 'three hundred mer }\end{array}$ & $\begin{array}{l}m i^{\prime} a t-i-n \\
\text { hundred-GEN-N }\end{array}$ & $\begin{array}{l}\min \\
\text { of }\end{array}$ & $\begin{array}{l}\text { al-rijal-i } \\
\text { the-man-GEN }\end{array}$ \\
\hline 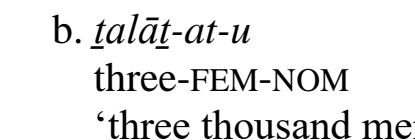 & $\begin{array}{l}\text { 'alā } f-i-n \\
\text { thousands-GEN-N } \\
\text { n' }\end{array}$ & $\begin{array}{l}\min \\
\text { of }\end{array}$ & $\begin{array}{l}\text { al-rijal- } i \\
\text { the-man-GEN }\end{array}$ \\
\hline
\end{tabular}

The question now is how digits are connected to express higher numeric values up to infinity? The answer is straightforward and simple; numerals can be combined to indicate one of two mathematical relations, viz., addition (e.g., 1,014 is 1000 added to 14) or multiplication (e.g., 14,000 is 1000 multiplied by 14) or both (e.g., 11,014). These two relations are expressed by the Multi\# head which has a null phonetic realization (similar to that in Indo-European languages, see, e.g., Di Sciullo, 2012) and imposes a low-high order (i.e., the digit with the lower numeric value must precede the one with higher value), and Add\# head which is realized as wa 'and' (cf., e.g., Dutch en, German und, and Biblical Welch $a(c)$, in Ionin \& Matushansky, 2018) imposes the opposite high-low pattern.

To illustrate, let us consider how the first digit (i.e., simple ' 4 ' or complex ' 40 '), in (42a,b) respectively, determines the syntactic realization of the multiplied numeral which behaves exactly as a counted noun, hence they do not share the same case assigned or plurality (i.e., ' 1000 ' is genitive plural noun whereas ' $1,000,000$ ' is accusative singular noun):
42) a. 'arba'-at-u
'ālāf-i-n
four-FEM-NOM
thousands-GEN-N
'four thousand'
b. 'arba' $-\bar{u}-n$
four-MASC.PL.NOM-N
malyūn-a-n
'fourty million'
milion-ACC-N 
While in these examples, the null Multi\# between the two digits imposes the low-high word order, the Add\# in (43) imposes the opposite pattern and requires the numerals to be separate DPs that share the same nominative case, as they do in a regular conjunction phrase:

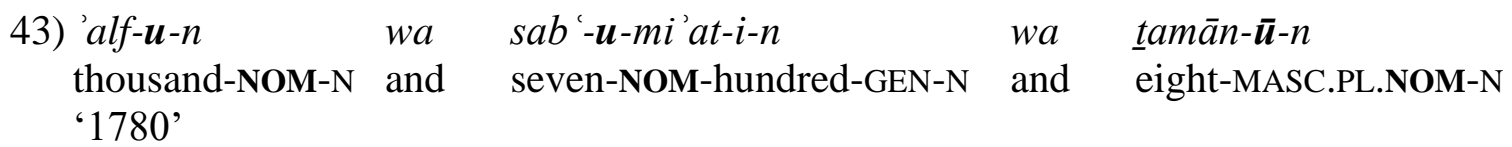

The different word orders required by Add\# and Multi\# in Arabic complex numerals seem consistent across languages, as highlighted by Ionin \& Matushansky (2018:121), "multiplicative and additive complex cardinals typically differ with regard to word order. While multiplicative complex cardinals typically exhibit the order low-high, the opposite is usually the case for additive complex cardinals".

The remaining question for this paper is what happens to the counted noun when it is preceded by different types of numerals (i.e., simplex, compound, and complex) as in (43). We highlight that only the last numeral in the sequence determines the case, number, and definiteness of the counted noun simply because the last numeral is the first constituent that connects with the counted noun and raises to a c-commanding position where it can determine the syntactic behavior of the counted noun. In (43), only ' 80 ' determines that a counted noun, for example, rajul 'man' to be rajul-a-n 'man-ACC-N', the other numerals '1000' and '700' cannot since they do not directly c-command rajul. This supports the view (e.g., Di Sciullo, 2012, 2017; Ionin \& Matushansky, 2006) that complex cardinals are formed by a recursive combinatorial operation that requires one and only one cardinal (regardless of its morphological complexity) to be merged with the counted noun for case, gender, and number valuation purposes, and then the formed NNC can merge with other cardinals in a high-low order, as in the given example.

\section{Lexical category of ' 1 ' and ' 2 '}

The general consensus in the literature that 'one' and 'two' are adjectives whereas the other simple cardinals are nouns seems questionable since a careful, detailed description of these cardinals shows that they can be both adjectival and nominal depending on their pre-nominal and post-nominal position, respectively. The numeral wähid 'one' can be an attributive adjective, and in this case, it shows all the characteristics of adjectives such as the following: (i) it occupies a postnominal position, (ii) it shows agreement with the noun it modifies in definiteness, number, and gender, as exemplified in (44a), (iii) it requires the dual markers - $\bar{n}$ (NOM) and -ayn (GEN/ACC) when it modifies a noun in the dual form, as in (44b), and the sound masculine, rather than the broken, plural form when it defines a plural noun (e.g., wähidīn 'one by one'), as in (44c):
44) a. marar-tu
bi-rajul-i-n
wāhid-i-n
passed-I by-man-GEN-N
one-MASC.GEN-N

'I passed by one man.'

$\begin{array}{lll}\text { b. } \text { marar-tu } & \text { bi- rajul-ayn } & \text { wāhid-ayn } \\ \text { passed-I } & \text { by-man-DUAL.GEN } & \text { single-DUAL.GEN } \\ \text { 'I passed by two single men.' } & \end{array}$


$\begin{array}{lll}\text { c. } \text { marar-tu } & \text { bi-rijāl-i-n } & \text { wāhid-īn } \\ \text { passed-I } & \text { by-men-GEN-N } & \text { single-MASC.PL.GEN }\end{array}$

'I passed by separate men. (e.g., who are standing one by one, rather than gathered as a group)'

The cardinal 'one' can also be a noun which has two forms, viz., wāhid and 'ahad. Concerning the first form, 'one' behaves as a NP in a DP, as in (45) which demonstrates that 'one' forms a DP in the complement position of the preposition bi- 'by'. In contrast with adjectival 'one' above, its dual form does not attach to a dual marker (e.g., *wähid-ayn); instead, it has an entirely different form (i.e., 'itnān 'two'), and the plural form is either the broken 'uhdān 'isolated people or things' or a different form denoting cardinality such as talāta 'three', 'arab 'ah 'four', etc., and it does not take a feminine marker -at (i.e., *wăhid-at), but it changes to 'ihdō 'one.FEM'. Furthermore, in constructions where it follows a noun, it behaves syntactically as an appositive, rather than as the adjectival 'awhd 'single' which does not change for gender or number. Notice in (46a) 'arba' 'four' is parallel to nis $\bar{a}$ ' 'women' as the two nouns have the same referent, whereas in (46b) 'awhd 'single' serves as an adjective which describes nis $\bar{a}$ ' 'women'. The differences in form and meaning between the nominal 'one' and the adjectival 'one' in (46a,b), respectively, are illuminating.
45) marar-tu $\quad$ bi-wāhid-i-n
passed-I by-one-GEN-N
'I passed by one person.'
46) a. marar-tu bi-nisa $\bar{a}^{\prime}-i-n \quad$ 'arba' $-i-n$
passed-I by-women-GEN-N four-GEN-N
'I passed by four women.'
b. marar-tu
$b i-n i s \bar{a}^{\prime}-i-n$
'awhad-i-n
passed-I
by-women-GEN-N
single-GEN-N
'I passed by isolated women.'

The form 'ahad behaves like other nominals in the following sentences. First, it must be preceded by a negative element (e.g., $m \bar{a}$ 'not'), as in (46a). Second, it can be preceded by the preposition min 'of' whose optional presence does not affect the grammaticality of the sentence, as in (46b). Third, although 'ahad 'one' usually refers to one entity, it may also refer to a group of entities, as evidenced in the plural agreement on the adjective hājiz 'preventive/barrierlike' and the nominal 'ahad 'one', as demonstrated in (46c). Fourth, it has a distinct word for the feminine gender (i.e., 'ihd $\bar{a}$ 'one.FEM') that is formed in the lexicon, rather than morphologically derived by adding the feminine marker -at (i.e., *'ahad-at). Fifth, unlike the adjectival wähid 'one' which adds a sense of definiteness to the noun it follows, 'ahad must be followed by a noun or a pronoun, and it means 'indefinite, unspecified entity', as the contrast in (46d) shows.
47) a. *(mā)
$j \bar{a}{ }^{\prime} a-n \bar{\imath}$
'ahad-u-n
not came-me
someone-NOM-N

'No one came to me.' 


$\begin{array}{llll}\text { b. } m \bar{a} & j \bar{a}^{\prime} a-n \bar{l} & (\min ) & \text { 'ahad-i-n } \\ \text { not } & \text { came-me } & \text { of } & \text { someone-GEN-N }\end{array}$

'No one came to me.'

\begin{tabular}{|c|c|c|}
\hline $\begin{array}{l}\text { c. } m \bar{a} \\
\text { not }\end{array}$ & $\begin{array}{l}\text { min-kum } \\
\text { of-you }\end{array}$ & $\begin{array}{l}\min \\
\text { of }\end{array}$ \\
\hline
\end{tabular}

'There is no one of you who could prevent [Us] from him.' (Qurān:Al-ḥāqa:47)

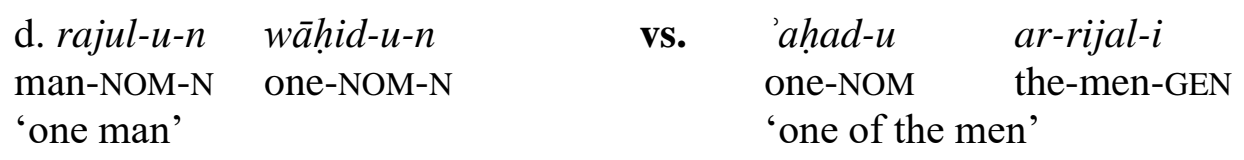

The numeral 'two' has two forms for masculine and feminine, and it also shows case

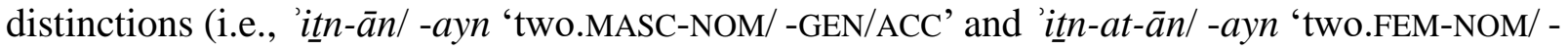
GEN/ACC'). Disagreeing with the prevalent consensus in the literature that 'two' is only adjectival, we claim that this numeral can also be nominal, as evidenced in its occurrence without a modified noun in the complement position of a preposition in (48a) and its position as the complement of the ordinal numeral 'second' in (48b) (i.e., as the genitive noun in the CS headed by 'second'), notice that adjectives cannot be the complement of prepositions or ordinals in Arabic. Furthermore, it occupies the same position like other nominal cardinals, namely, prenominally (a position not allowed for adjectives), as evidenced in Classical Arabic poetry in (48c) (see, e.g., Al-Mubarrad, 1994:153)
48) a. 'in kun-na nisā'-a-n fawqa 'itn-at-ayn
if were-they women-ACC-N PREP two-FEM-GEN
'if they are more than two females'

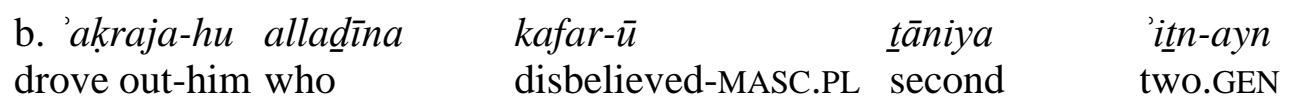

'the disbelievers drove him out, the second of two.'

(Quran: At-tawba:40)

\section{c. $\underline{\text { tint }} \bar{a} \quad$ handal $-i-n$ \\ two bitter apple-GEN-N}

'two bitter apples'

The morphological structure of 'two' is illuminating as it leads to significant implications on the dual marker in Arabic. The forms 'ithn-ān/-ayn 'two.MASC-NOM/-GEN/ACC' are composed of two elements, viz., 'ithn, and -ān/ -ayn. The first element 'ithn is a bound morpheme which cannot be assumed to be singular for the absence of a plural form derived from it, and it cannot be said to be dual as the addition of the dual marker to it would be an unjustified redundancy, and it cannot be plural since dual marker cannot attach to plural forms except in words which denote a group of entities, rather than individuated ones (e.g., jimāl 'camels' $=>$ jimāl-ān 'two groups of camels'). Assuming the correcting of this assumption, we claim that 'two' enters the derivation as 'ithn, a root unspecified for number which gets its number from the dual marker which cannot be said to be a single morpheme, as argued in the literature, for the simple reason that it has three separate morphemes, each of which has distinct syntactic properties. The first morpheme is the dual marker $-a$ which is a substitute for the omitted second noun conjoined to the first one, that is, a dual form, for example, rajul-ān 'man-DUAL' stands for a conjunction of 
two nouns 'man' and 'man', the second noun is omitted and replaced by the dual marker since it has the same form and meaning as the first noun (for a similar view, see Kayne, 2016). The second element is the case marker which is $-a$ for nominative and $-y$ for genitive and accusative in rajul-aan and rajul-ayn, respectively. The third element is the nasal $-n$ which behaves like nunation in its obligatory deletion in CSs, as demonstrated in (49a,b).

\begin{tabular}{|c|c|c|c|}
\hline $\begin{array}{l}\text { 49) a. kitab-u-n } \\
\text { book-NOM-N } \\
\text { 'a book' }\end{array}$ & VS. & $\begin{array}{l}\text { kitab-u- }\left(*_{n}\right) \\
\text { book-NOM- }\left(*^{*}\right) \\
\text { 'the student's book' }\end{array}$ & $\begin{array}{l}a t+t \underline{a} l i b-i \\
\text { the-student-GEN }\end{array}$ \\
\hline $\begin{array}{l}\text { b. kitab- } \bar{a}-n \\
\text { book-DUAL.NOM-N } \\
\text { 'two books' }\end{array}$ & VS. & $\begin{array}{l}\text { kitab- } \overline{-}-\left(*^{*} n\right) \\
\text { book-DUAL.NOM- }\left({ }^{*} \mathrm{~N}\right. \\
\text { 'the student's two bo }\end{array}$ & $\begin{array}{l}a t-t a \bar{l} l i b-i \\
\text { the-student-GEN } \\
\text { oks }\end{array}$ \\
\hline
\end{tabular}

However, in contrast with nunation in singular forms, the $-n$ in the dual form must coexist with

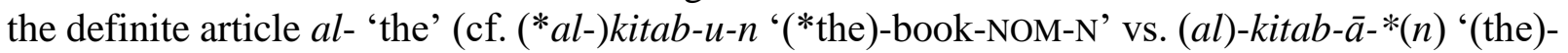
book-DUAL.NOM-N'). The peculiarity of this phenomenon can be straightforwardly accounted for assuming that singular forms enter the derivation unspecified for number and definiteness, that is, the features [NUM] and [DEF] exist in separate functional heads, namely, Num and D, respectively, in the extended projection of NP whereas, in dual forms, the dual marker has a bundle of features [NUM, DEF], that is, the noun is both dual and definite simultaneously, as evidenced in the grammaticality of attaching nunation (i.e., the indefinite article $-n$ ) in, e.g., $k i t a b-\bar{a}-n$, which changes the inherent [DEF] to [INDEF]. This claim can be supported by the ungrammaticality of adding the definite article $a l$ - to the dual form lacking nunation (e.g., (*al)$k i t a b-\bar{a})$ as it is already definite by the feature [DEF] which is bundled with [NUM] in the dual marker $-a$.

\section{Summary and conclusion}

In this paper, the analysis of Arabic NNCs shows that numerals are lexical elements with both nominal and adjectival properties depending on their pre- and post-nominal positions, respectively. This analysis follows a unified approach that deviates from previous studies that argue for treating numerals as functional heads.

Concerning simple cardinals (i.e., 1-10, 100, 1,000, etc.,), we have shown that all of them have the same syntactic characteristics and position of quantifiers (Qs). This argument does not only provide a straightforward account for the genitive case assignment but also explains the lexical category of all simple cardinals including ' 1 ' and ' 2 ' in a unified proposal. Contra previous studies, ' 1 ' and ' 2 ' are explained to be not always adjectival, but nominal as well, depending on the different forms these numerals have which show different properties unrelated to adjectives, such as their position as the complement of a preposition or an ordinal numeral, and their position preceding the counted noun like other nominal cardinals. The discussion of ' 2 ' leads to the analysis of the dual marker as constituting of three distinct morphemes, viz., the dual marker $-a$ which is a substitute for the omitted second noun, the case marker $-a /-y$, and the nunation-like $-n$. The peculiarities of $-n$ in singular forms compared with dual forms suggest that singular forms enter the derivation unspecified for number and definiteness, that is, the features [NUM] and [DEF] exist in separate functional heads, namely, Num and D, respectively, whereas 
dual forms enter the derivation with the dual marker which has a bundle of features [NUM, DEF], that is, the noun is both dual and definite simultaneously. Gender polarity is argued to be a morphological process that requires all simple cardinals to have the opposite gender with the counted noun since they enter the derivation with unvalued reverse gender agreement feature [URG]. This process applies to all simple nominal cardinals unless it is blocked by lexical processes that determine the gender of a numeral such as ' 1 ', ' 2 ', ' ' 100 ', ' 1,000 '.

Compound numerals (e.g., '13') in post-nominal position are analyzed to be formed of two Ns which enter the derivation as an unordered set $\{\mathrm{N}, \mathrm{N}\}$ in an exocentric and symmetric relationship, and to linearize them and to reflect their semantics, we assume the functional head Add\# c-commands the unordered set and requires the digit with the lower numeric value to move based on the fact it is the only $\mathrm{N}$ which can attach to al- 'the' due to its unvalued [DEF] feature. The given derivations explain the right word order in which the digit with the lower value must precede the other digit and provide the configuration which explains why both digits cannot receive the indefinite article $-n$, why only the first digit allows the attachment of $a l-$, and why only the first digit has a reverse gender feature. The movement of the compound numerals to a prenominal is argued to be triggered by the $\mathrm{Ra}$ 'restrictive accusative' head that requires the counted noun to be accusative, indefinite, and generic, hence, the change of the case and form of the counted noun in tamyiz 'restrictive accusative' constructions. The existence of Ra head is claimed to be essential since it enables the connection of two DPs in Arabic not only in NNCs but also in other combinations of two DPs which have two Ns assigned the accusative case by Ra.

The analysis complex numerals (e.g., '12', '30') shows that another type of Num head exists, viz., Multi\#, which requires its complement to be specified for gender, hence, the absence of gender polarity process in all multiplicative cardinals. Similar to compound numerals, the prenominal position of complex cardinals triggers the change of plurality, definiteness, and case of the counted noun because the structure is headed by Ra head that requires the movement of the numeral to its spec position and the assignment of the accusative case to its complement. The last issue discussed in the paper involves the explanation of why simplex, compound, and complex cardinals include only a limited set of cardinals and not other ones. This issue is argued to be related to the nature of the Num head (i.e., Add\# or Multi\#) which cannot have a specifier and a complement of the same numeric value within the same formed DP, as it requires the digit with the lower value to move higher, and since every DP cannot have more than two Num heads c-commanding its $\mathrm{N}$ as that would yield more mathematical processing within the same projection and conflicting number features assigned to the N. Assuming the correctness of this assumption, we argue that digits are connected to express higher numeric values up to infinity in a recursive combinatorial operation (i.e., by Merge) to indicate the mathematical relations of addition and/or multiplication. This assumption is essential as it explains the specific high-low order in Arabic and across languages as well as the reason why one and only one cardinal (i.e., only the last numeral in the sequence) can merge with the counted noun for case, gender, and number valuation purposes, and then the formed NNC can merge with other cardinals in a highlow order for mathematical, rather than linguistic, motives.

Briefly stated, the paper claims that the set of functional heads made possible by UG includes analogs to the arithmetic functions of addition and multiplication. The inclusion of these functional heads in the grammatical analysis of Arabic NNCs makes possible a principled account of complex data in Arabic quantificational expressions, especially numerical DPs as 
they include several peculiarities involving case assignment, definiteness and specificity, and word order. However, the given discussion implies the support of Merge as a mechanism unique to humans, as indicated by Hauser, Chomsky, \& Fitch (2002:15, cited in Hiraiwa, 2017:2) "in parallel with the faculty of language, our capacities for number rely on a recursive computation," simply because "operating without bounds, Merge yields a discrete infinity of structured expressions” (Chomsky, 2007:5).

\section{References}

Al-Ansari, I. H. (1991). Mughni Al-Labib (M. Abd Al-Hamid, Ed.). Al Asriyyah Library. https://www.alkitab.com/50065.html

Al-Bataineh, H. (2019). Emphasis Harmony in Arabic: A Critical Assessment of Feature-Geometric and Optimality-Theoretic Approaches. Languages, 4(4), 79. https://doi.org/10.3390/languages4040079

Al-Bataineh, H. (2020). The Syntax of Arabic Vocatives. Brill's Journal of Afroasiatic Languages and Linguistics. https://doi.org/10.1163/18776930-01202100

Alexiadou, A. (2014). The syntax of adjectives. In The Routledge Handbook of Syntax (pp. 107125). Routledge.

Al-Mubarrad, M. (1994). Al-MuqTad̦ab (M. 'Ad̦iymah, Ed.). Ministry of Religious Endowments.

Alqarni, M. (2015). The morphosyntax of numeral-noun constructions in Modern Standard Arabic [Ph.D., University of Florida].

Alqassas, A. (2017). Gender and number polarity in Modern Standard Arabic numeral phrases. Canadian Journal of Linguistics/Revue Canadienne de Linguistique, 62(1), 1-17.

Aqeel, I. (1980). Sharh Ibn Aqeel of the Alfiyyah of Ibn Malik (20th ed.). Dar Masir.

Asinari, S. (2019). Case Percolation in Russian Numeral Constructions. University of Pennsylvania Working Papers in Linguistics, 25(1).

Bailyn, J. F. (2004). The case of Q. Proceedings of FASL, 12, 1-35.

Borer, H. (2005). Structuring Sense: Volume I: In Name Only: Vol. 1: In Name Only. Oxford University Press.

Cantarino, V. (1976). Syntax of Modern Arabic Prose: The Expanded Sentence v. 2 (International Development Research Center. Studies in development, no. 5) (Vol. 2). Indiana University Press.

Chomsky, N. (2007). Approaching UG from below. In U. Sauerland \& H.-M. Gärtner (Eds.), Interfaces + recursion = language? Chomsky's minimalism and the view from syntaxsemantics (pp. 1-30). Mouton de Gruyter.

Cinque, G. (2010). The syntax of adjectives: A comparative study (Vol. 57). MIT press.

Corbett, G. G. (1978). Universals in the syntax of cardinal numerals. Lingua, 46(1), 61-74. https://doi.org/10.1016/0024-3841(78)90054-2

Cowan, D. (1958). An Introduction to Modern Literary Arabic. Cambridge University Press. 
Danon, G. (2009). Grammatical number in numeral-noun constructions. CGG-19, April, 1-3.

Danon, G. (2012). Two structures for numeral-noun constructions. Lingua, 122(12), 1282-1307. https://doi.org/10.1016/j.lingua.2012.07.003

Di Sciullo, A. M. (2012). Asymmetry in complex numerals. Talk given at Harvard University.

Di Sciullo, A. M. (2017). Asymmetry and the Language Faculty. Revista Linguíftica, 13(2), 88. https://doi.org/10.31513/linguistica.2017.v13n2a14030

Franks, S. (1994). Parametric properties of numeral phrases in Slavic. Natural Language \& Linguistic Theory, 12(4), 597-674. https://doi.org/10.1007/BF00992929

Hahn, E. A. (1960). The Origin of the Greek Accusative in Latin. Transactions and Proceedings of the American Philological Association, 91, 221-238. https://doi.org/10.2307/283855

Hauser, M. D., Chomsky, N., \& Fitch, W. T. (2002). The faculty of language: What is it, who has it, and how did it evolve? Science, 298(5598), 1569-1579.

Haywood, J. A., \& Nahmad, H. M. (1965). A new Arabic grammar of the written language (2nd edition). Lund Humphries.

He, C. (2015). Complex numerals in Mandarin Chinese are constituents. Lingua, 164, 189-214. https://doi.org/10.1016/j.lingua.2015.06.014

Hiraiwa, K. (2017). The Faculty of Language Integrates the Two Core Systems of Number. Frontiers in Psychology, 8. https://doi.org/10.3389/fpsyg.2017.00351

Hurford, J. R. (1975). The Linguistic Theory of Numerals. Cambridge University Press.

Hurford, J. R. (1998). The interaction between numerals and nouns. In F. Plank (Ed.), Noun phrase structure in the languages of Europe (pp. 561-620). European Science Foundation.

Ibn Mālk, M. (1990). Šarḥ Attashīl Lābn Mālk ( Abd Arraḥmn Assayd \& M. Almaḳtūn, Eds.; Vol. 3). Dār Hajr.

Ionin, T., \& Matushansky, O. (2006). The Composition of Complex Cardinals. Journal of Semantics, 23(4), 315-360. https://doi.org/10.1093/jos/ffl006

Ionin, T., \& Matushansky, O. (2018). Cardinals: The syntax and semantics of cardinalcontaining expressions. MIT Press.

Jackendoff, R. (1977). X syntax: A study of phrase structure. MIT press.

Kayne, R. S. (2007). Silent years, silent hours. In Movement and silence. Oxford University Press.

Kayne, R. S. (2010). Comparisons and contrasts. Oxford University Press.

Kayne, R. S. (2016). "Some Thoughts on One and Two and Other Numerals"-Lingbuzz/002991 [Unpublished manuscript]. https://ling.auf.net/lingbuzz/002991

Khalaf, E. A. (2019). Floating quantifiers are autonomous phrases: A movement analysis. Glossa: A Journal of General Linguistics, 4(1), 89. https://doi.org/10.5334/gjgl.848

Kirk, W. H. (1919). The Accusative of Specification in Latin. Classical World, 13, 98-101. 
Kouloughli, D. E. (1994). Grammaire de l'arabe d'aujourd'hui. Pocket.

Marcin, M. (2016). Agreement in Modern Standard Arabic constructions with cardinal numerals over ten. Lingua Posnaniensis, 58(1), 69-88. https://doi.org/10.1515/linpo-2016-0005

Meek, T. J. (1940). The Hebrew accusative of time and place. Journal of the American Oriental Society, 60(2), 224-233.

Meek, T. J. (1945). The syntax of the sentence in Hebrew. Journal of Biblical Literature, 64(1), $1-13$.

Norris, M. J. (2018). The morphosyntax of number in Estonian numeral-noun constructions. Proceedings of the Linguistic Society of America, 3(1), 45-1-13. https://doi.org/10.3765/plsa.v3i1.4337

Ouhalla, J. (2013). Agreement unified: Arabic. In L. L.-S. Cheng \& N. Corver (Eds.), Diagnosing Syntax (pp. 314-333). Oxford University Press.

Ritter, E. (1992). Cross-Linguistic Evidence for Number Phrase. Canadian Journal of Linguistics/Revue Canadienne de Linguistique, 37(2), 197-218. https://doi.org/10.1017/S0008413100021952

Rutkowski, P., \& Szczegot, K. (2001). On the Syntax of Functional Elements: Numerals, Pronouns, and Expressions Indicating Approximation. Generative Linguistics in Poland: Syntax and Morphosyntax, 187-196.

Ryding, K. C. (2005). A Reference Grammar of Modern Standard Arabic (1st edition). Cambridge University Press.

Shlonsky, U. (2004). The form of Semitic noun phrases. Lingua, 114(12), 1465-1526. https://doi.org/10.1016/j.lingua.2003.09.019

Sibawayh, A. B. (1988). Al-Kitāb [The Book] (A. Haroon, Ed.; 3rd ed., Vol. 1). Al Khanji Library.

Valois, D. (2006). Adjectives: Order within DP and Attributive APs. The Blackwell Companion to Syntax, 61-82.

Winder, R. B., \& Ziyadeh, F. J. (2019). Introduction to Modern Arabic (Vol. 5500). Princeton University Press.

Witkoś, J., \& Dziubała-Szrejbrowska, D. (2018). Cardinal numerals and complex numerals as specifiers. Poznan Studies in Contemporary Linguistics, 54(4), 605-635. https://doi.org/10.1515/psicl-2018-0024

Ya'īsh, 'Ibin. (2001). Sharh Al-mufaSSal Lil-Zamaxsharī ('Imīl Ya'qūb, Ed.; 1st ed., Vol. 4). Dar Al-Kotob Al-ilmyah. 